Article

\title{
Gene Prioritization through Consensus Strategy, Enrichment Methodologies Analysis, and Networking for Osteosarcoma Pathogenesis
}

\author{
Alejandro Cabrera-Andrade ${ }^{1,2,3, *(D)}$, Andrés López-Cortés ${ }^{3,4}$ (D), \\ Gabriela Jaramillo-Koupermann ${ }^{5}$ (D) César Paz-y-Miño 4 (D), Yunierkis Pérez-Castillo ${ }^{1,6}$,

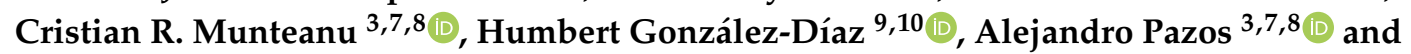 \\ Eduardo Tejera 1,11,* \\ 1 Grupo de Bio-Quimioinformática, Universidad de Las Américas, Quito 170125, Ecuador; \\ yunierkis.perez@udla.edu.ec \\ 2 Carrera de Enfermería, Facultad de Ciencias de la Salud, Universidad de Las Américas, \\ Quito 170125, Ecuador \\ 3 RNASA-IMEDIR, Computer Sciences Faculty, University of A Coruna, 15071 A Coruña, Spain; \\ aalc84@gmail.com (A.L.-C.); c.munteanu@udc.es (C.R.M.); apazos@udc.es (A.P.) \\ 4 Centro de Investigación Genética y Genómica, Facultad de Ciencias de la Salud Eugenio Espejo, \\ Universidad UTE, Quito 170129, Ecuador; cesar.pazymino@ute.edu.ec \\ 5 Laboratorio de Biología Molecular, Subproceso de Anatomía Patológica, Hospital de Especialidades Eugenio \\ Espejo, Quito 170403, Ecuador; gaby_jaramillok@yahoo.com \\ 6 Escuela de Ciencias Físicas y Matemáticas, Universidad de Las Américas, Quito 170125, Ecuador \\ 7 Biomedical Research Institute of A Coruña (INIBIC), University Hospital Complex of A Coruña (CHUAC), \\ 15006 A Coruña, Spain \\ 8 Centro de Investigación en Tecnologías de la Información y las Comunicaciones (CITIC), Campus de Elviña \\ s/n, 15071 A Coruña, Spain \\ 9 Department of Organic Chemistry II, University of the Basque Country UPV/EHU, 48940 Leioa, Spain \\ 10 IKERBASQUE, Basque Foundation for Science, 48011 Bilbao, Spain; humberto.gonzalezdiaz@ehu.es \\ 11 Facultad de Ingeniería y Ciencias Agropecuarias, Universidad de Las Américas, Quito 170125, Ecuador \\ * Correspondence: raul.cabrera@udla.edu.ec (A.C.-A.); eduardo.tejera@udla.edu.ec (E.T.); \\ Tel.: +593-2398-1000 (ext. 2717) (A.C.-A.); +593-2398-1000 (ext. 713) (E.T.)
}

Received: 10 December 2019; Accepted: 30 January 2020; Published: 5 February 2020

check for updates

\begin{abstract}
Osteosarcoma is the most common subtype of primary bone cancer, affecting mostly adolescents. In recent years, several studies have focused on elucidating the molecular mechanisms of this sarcoma; however, its molecular etiology has still not been determined with precision. Therefore, we applied a consensus strategy with the use of several bioinformatics tools to prioritize genes involved in its pathogenesis. Subsequently, we assessed the physical interactions of the previously selected genes and applied a communality analysis to this protein-protein interaction network. The consensus strategy prioritized a total list of 553 genes. Our enrichment analysis validates several studies that describe the signaling pathways PI3K/AKT and MAPK/ERK as pathogenic. The gene ontology described TP53 as a principal signal transducer that chiefly mediates processes associated with cell cycle and DNA damage response It is interesting to note that the communality analysis clusters several members involved in metastasis events, such as MMP2 and MMP9, and genes associated with DNA repair complexes, like ATM, ATR, CHEK1, and RAD51. In this study, we have identified well-known pathogenic genes for osteosarcoma and prioritized genes that need to be further explored.
\end{abstract}

Keywords: gene prioritization; osteosarcoma; communality analysis; pathogenesis; early recognition 


\section{Introduction}

In recent years, high-throughput technologies have focused on studying the molecular etiology of osteosarcoma (OS) worldwide [1-5]. Valuable information has been gained about whole genetic groups that describe cellular and molecular changes in OS [6,7]. Despite this, there has not been an agreement about specific driver genes for OS etiology, nor have new biomarkers been proposed to be used as therapeutic targets.

OS tumors are characterized by being heterogeneous and showing high rates of somatic structural variations. Their heterogeneity is closely related to their high rates of mutations, which are comparable to breast tumors and leukemia [8-10]. Moreover, cytogenetic abnormalities in OS tumors, including chromosomal segment loss, rearrangement, and amplification with karyotypic complexity in the absence of recurrent clonal translocations, have been described [11,12]. This acute chromosomal instability and widespread deregulation in cell signaling pathways could be the main limitations for the description of specific gene drivers associated with OS. It is therefore necessary to develop an integrative study focused on the biology of systems described for this tumor.

The use of prioritization strategies, through computational tools that use multiple heterogeneous data sources, allows for the improvement in gene detection related to complex traits or specific clinical phenotypes $[13,14]$. In addition, applying the functional enrichment analysis has proven to be a very efficient approach in gene prioritization because it describes important metabolic interactions that aid in explaining the pathogenesis of a given disease $[15,16]$. Thus, we used several bioinformatics tools in order to prioritize genes that describe oncological signaling pathways for OS and also applied a consensus strategy with the aim to specify and postulate new pathogenic mechanisms that explain the onset and development of this sarcoma. In Figure 1, we summarize the general workflow to prioritize genes associated with the pathogenesis of OS.

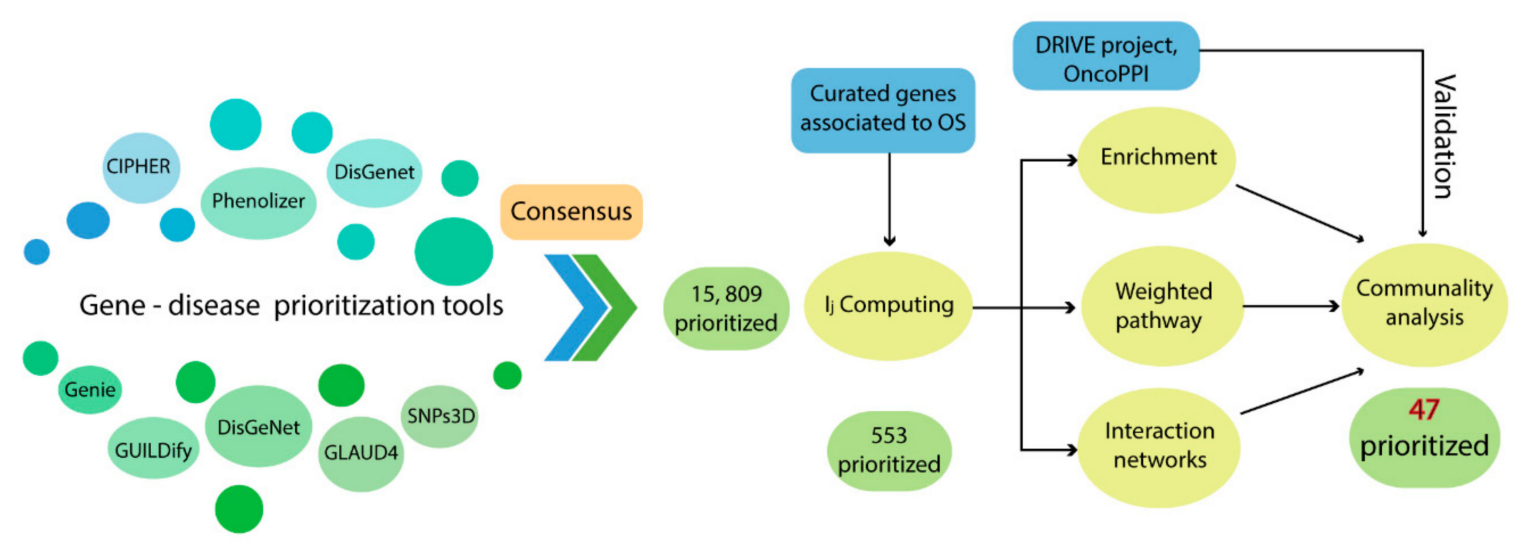

Figure 1. General workflow to gene prioritization.

\section{Results}

\subsection{Consensus Prioritization}

We chose nine bioinformatics methods that fulfilled two main criteria: full availability in web service platform and only requiring the disease name (or OMIN code, 259,500 for OS) for gene prioritization. In total, the combination of all methodologies resulted in 15,809 genes.

The validation strategy for gene prioritization was performed from the identification of specific genes involved in the OS pathogenesis. For this, we took into consideration pathogenic OS genes defined by a literature review of two types of studies: meta-analysis, based on publications and case reports for OS patients (named as G1 genes), and gene description in animal models and OS cell lines (named as G2 genes). Thereby, we identified 75 pathogenic OS genes from the available literature, of which 47 were classified as G1 and 41 as G2 (Table S1). 
The number of pathogenic genes detected by the nine prioritization tools was lower than our consensus strategy (Table 1). By comparing the number of pathogenic genes detected by all methodologies, our consensus list identifies the highest percentage of those defined as G1 and G2. Specifically, in the top $1 \%$ of our consensus method (the first 158 positions), $60 \%$ of pathogenic genes (45 of 75$)$ were detected, followed by Genie (35.29\%) and Phenolizer (30.14\%) methodologies. Furthermore, in the top $20 \%$, the consensus method remains the best at detecting pathogenic genes $(88 \%)$, followed by Genie, Phenolizer, and SNPs3D with percentages of $80.88 \%, 72.60 \%$, and $71.88 \%$, respectively.

Table 1. Identification (in \%) of pathogenic genes in each osteosarcoma (OS) approach.

\begin{tabular}{ccccccccccccc}
\hline \multirow{2}{*}{ Methods } & \multicolumn{3}{c}{$\mathbf{1 \%}$} & \multicolumn{3}{c}{$\mathbf{5 \%}$} & \multicolumn{3}{c}{$\mathbf{1 0} \%$} & \multicolumn{3}{c}{$\mathbf{2 0 \%}$} \\
\cline { 2 - 13 } & G1 & G2 & G1-2 & G1 & G2 & G1-2 & G1 & G2 & G1-2 & G1 & G2 & G1-2 \\
\hline BioGraph & 0 & 0 & 0 & 0 & 18.2 & 12.5 & 40 & 45.5 & 37.5 & 60 & 54.6 & 50 \\
CIPHER & 7.7 & 6.7 & 8.7 & 7.7 & 6.7 & 8.7 & 23.1 & 20 & 17.4 & 30.8 & 26.7 & 26.1 \\
DisGeNET & 9.5 & 16.7 & 10.8 & 21.4 & 30.6 & 21.5 & 42.9 & 58.3 & 46.2 & 57.1 & 77.8 & 64.6 \\
Genie & 37.8 & 36.1 & 35.3 & 62.2 & 61.1 & 57.4 & 75.6 & 69.4 & 70.6 & 86.7 & 75 & 80.9 \\
GLAD4U & 0 & 0 & 3.6 & 19.1 & 33.3 & 25 & 42.9 & 50 & 46.4 & 57.1 & 66.7 & 64.3 \\
GUILDify & 10.9 & 7.5 & 8.2 & 13 & 7.5 & 9.6 & 21.7 & 17.5 & 19.2 & 34.8 & 25 & 30.1 \\
Phenolizer & 33.3 & 36.6 & 30.1 & 57.8 & 61 & 53.4 & 62.2 & 61 & 56.2 & 77.8 & 75.6 & 72.6 \\
PolySearch & 0 & 0 & 0 & 11.1 & 14.3 & 7.1 & 11.1 & 28.6 & 14.3 & 11.1 & 28.6 & 14.3 \\
SNPs3D & 10 & 10.5 & 6.3 & 10 & 42.1 & 25 & 40 & 57.9 & 50 & 75 & 73.7 & 71.9 \\
Consensus & 66 & 61 & 60 & 87.2 & 80.5 & 81.3 & 89.4 & 82.9 & 84 & 93.6 & 85.4 & 88 \\
\hline
\end{tabular}

On the other hand, the mean ranking of the pathogenic genes detected in the top $1 \%$ of the list is 49.3 (Table 2), which means that 45 G1-G2 genes are located in the top 50 positions. This mean is higher than that calculated for the other prioritization methodologies, given that the number of pathogenic genes detected is greater. However, it is interesting to note that the number of genes and the ranking average are similar, which indicates that the majority of these pathogenic genes are found in the top positions.

Table 2. Rank of pathogenic genes in each OS approach.

\begin{tabular}{ccccccccccccc}
\hline \multirow{2}{*}{ Methods } & \multicolumn{3}{c}{$\mathbf{1 \%}$} & \multicolumn{3}{c}{$\mathbf{5 \%}$} & \multicolumn{3}{c}{$\mathbf{1 0 \%}$} \\
\cline { 2 - 13 } & G1 & G2 & G1-2 & G1 & G2 & G1-2 & G1 & G2 & G1-2 & G1 & G2 & G1-2 \\
\hline BioGraph & - & - & - & - & 3.5 & 3.5 & 7 & 6 & 6.3 & 9.5 & 7.3 & 8 \\
CIPHER & 2 & 7 & 4.5 & 2 & 7 & 4.5 & 41.3 & 43 & 32.8 & 58 & 59 & 57.7 \\
DisGeNET & 5.3 & 4.2 & 4.7 & 12.1 & 10 & 11.1 & 23.9 & 23.6 & 25.2 & 31.6 & 31.4 & 33.7 \\
Genie & 17 & 14.6 & 16.5 & 44 & 41.6 & 42.6 & 88.2 & 75 & 91.3 & 148.5 & 113.2 & 151.9 \\
GLAD4U & - & 1 & 1 & 4 & 4.2 & 4 & 8.6 & 6.6 & 8.2 & 13.3 & 10.2 & 13 \\
GUILDify & 15.8 & 8.3 & 16.7 & 42.6 & 8.3 & 43.3 & 366.5 & 536.4 & 491.2 & 873.8 & 973.9 & 972.1 \\
Phenolizer & 44.3 & 28 & 36.4 & 150.4 & 120.9 & 148 & 200.9 & 120.9 & 182.5 & 477.5 & 429.2 & 513.2 \\
PolySearch & - & - & - & 2 & 2 & 2 & 2 & 2.5 & 2.5 & 2 & 2.5 & 2.5 \\
SNPs3D & 1.5 & 1.5 & 1.5 & 1.5 & 6.4 & 4 & 17.8 & 10.9 & 14.4 & 27.1 & 16.2 & 21.6 \\
Consensus & 54.5 & 41.6 & 49.3 & 126.1 & 108.2 & 128 & 152.9 & 131.2 & 157.7 & 241.4 & 174.7 & 239.3 \\
\hline
\end{tabular}

This initial prioritization generated an initial amount of 15,809 genes, so a rational cut-off was applied. The maximum variation between Ii and the gene ranking was 0.7609 , corresponding with a ranking value of 553. Therefore, this cut-off reduces a list of 15,809 members to a consensus of 553 genes (Table S2), which corresponds to $3.5 \%$ of the total. The rate of pathogenic detection of the consensus was $87.2 \%$ for G1 (41 out of 47 ), $80.5 \%$ for G2 (33 out of 41 ), and $81.3 \%$ for G1 and G2 (61 out of 75), higher than the other methods in the top $5 \%$ onwards.

\subsection{Enrichment Analysis of OS Related Genes and the Protein-Protein Interaction Network}

A gene ontology (GO) analysis and pathway enrichment analysis was applied in order to describe biological functions from the consensus genes by using the David Bioinformatics Resource [17,18]. The GO analysis of these 553 consensus genes resulted in 263 terms related to biological processes 
(Table S3), adjusted to an FDR $p$-value $<0.01$. Using Revigo [19] and only considering terms with a frequency lower than $0.01 \%$, we narrowed our list down to 92 (Table S4). Some of these specific biological processes are listed in Table 3.

Table 3. Some biological processes by enrichment analysis in OS consensus genes.

\begin{tabular}{|c|c|c|c|}
\hline BP ID & Name & Frequency & Log10 p-Value (FDR) \\
\hline GO:1901796 & $\begin{array}{l}\text { regulation of signal transduction } \\
\text { by p53 class mediator }\end{array}$ & $0.01 \%$ & -22.8416 \\
\hline GO:0006977 & $\begin{array}{l}\text { DNA damage response, signal } \\
\text { transduction by p53 class mediator } \\
\text { resulting in cell cycle arrest }\end{array}$ & $0.00 \%$ & -20.1656 \\
\hline GO:0048661 & $\begin{array}{l}\text { positive regulation of smooth } \\
\text { muscle cell proliferation }\end{array}$ & $0.01 \%$ & -16.5544 \\
\hline GO:0048146 & $\begin{array}{l}\text { positive regulation of } \\
\text { fibroblast proliferation }\end{array}$ & $0.01 \%$ & -16.5031 \\
\hline GO:0045740 & $\begin{array}{l}\text { positive regulation of } \\
\text { DNA replication }\end{array}$ & $0.01 \%$ & -15.1965 \\
\hline GO:1902895 & $\begin{array}{l}\text { positive regulation of pri-miRNA } \\
\text { transcription from RNA } \\
\text { polymerase II promoter }\end{array}$ & $0.00 \%$ & -14.983 \\
\hline GO:0043525 & $\begin{array}{l}\text { positive regulation of neuron } \\
\text { apoptotic process }\end{array}$ & $0.01 \%$ & -14.9393 \\
\hline GO:0071260 & $\begin{array}{l}\text { cellular response to } \\
\text { mechanical stimulus }\end{array}$ & $0.01 \%$ & -13.3507 \\
\hline GO:0032355 & response to estradiol & $0.01 \%$ & -11.7258 \\
\hline GO:0045669 & $\begin{array}{l}\text { positive regulation of } \\
\text { osteoblast differentiation }\end{array}$ & $0.01 \%$ & -11.5058 \\
\hline GO:0060395 & $\begin{array}{l}\text { SMAD protein signal transduction } \\
\text { intrinsic apoptotic signaling }\end{array}$ & $0.01 \%$ & -11.1904 \\
\hline GO:0042771 & $\begin{array}{l}\text { pathway in response to DNA } \\
\text { damage by p53 class mediator }\end{array}$ & $0.01 \%$ & -10.8356 \\
\hline GO:0097192 & $\begin{array}{l}\text { extrinsic apoptotic signaling } \\
\text { pathway in absence of ligand }\end{array}$ & $0.01 \%$ & -10.0846 \\
\hline GO:0035019 & $\begin{array}{l}\text { somatic stem cell } \\
\text { population maintenance }\end{array}$ & $0.01 \%$ & -9.6162 \\
\hline GO:0010332 & response to gamma radiation & $0.01 \%$ & -9.4056 \\
\hline GO:0002053 & $\begin{array}{l}\text { positive regulation of } \\
\text { mesenchymal cell proliferation }\end{array}$ & $0.01 \%$ & -9.2628 \\
\hline GO:0002076 & osteoblast development & $0.00 \%$ & -9.1046 \\
\hline GO:0048538 & thymus development & $0.01 \%$ & -8.2907 \\
\hline GO:0048010 & $\begin{array}{l}\text { vascular endothelial growth factor } \\
\text { receptor signaling pathway }\end{array}$ & $0.01 \%$ & -7.6946 \\
\hline GO:0010718 & $\begin{array}{l}\text { positive regulation of epithelial to } \\
\text { mesenchymal transition }\end{array}$ & $0.01 \%$ & -7.6126 \\
\hline
\end{tabular}

Likewise, the enriched metabolic pathways considered in KEGG and Reactome databases are shown in Tables S5 and S6. A partial list of the prioritized metabolic pathways with an FDR $p<0.01$ is presented in Table 4.

The enriched biological processes of the 553 genes describe terms associated with positive DNA replication, cellular proliferation, and apoptotic events, in which TP53 is one of the most relevant signal transducers. In addition, more specific sarcoma-related terms are listed, such as smooth muscle cell and fibroblast proliferation, osteoblast differentiation and development, and positive regulation of mesenchymal cell proliferation.

The pathway enrichment analysis showed pathways in cancer and the cell cycle in general. The enrichment from the KEGG database showed widely described signaling pathways in cancer in the top positions, for instance, FOXO, PI3K/AKT, TP53, MAPK, neurotrophin, and cell cycle. Moreover, the Reactome database lists events mainly related to cell cycle regulation such as cyclin D-associated 
events in G1, G0 and early G1; Cyclin A: Cdk2-associated events at S phase entry, and Cyclin A/B1 associated events during $\mathrm{G} 2 / \mathrm{M}$ transition.

Table 4. Pathways enrichment analysis using KEGG and Reactome databases in OS consensus genes.

\begin{tabular}{|c|c|c|c|}
\hline Pathway ID & Pathway Name & $\%$ Genes & FDR \\
\hline \multicolumn{4}{|c|}{ KEGG Database } \\
\hline hsa05200 & Pathways in cancer & 26.22 & $1.33 \times 10^{-8}$ \\
\hline hsa04110 & Cell cycle & 11.93 & $3.96 \times 10^{-45}$ \\
\hline hsa04068 & FoxO signaling pathway & 10.85 & $4.50 \times 10^{-35}$ \\
\hline hsa04151 & PI3K-Akt signaling pathway & 15.55 & $1.98 \times 10^{-29}$ \\
\hline hsa05206 & MicroRNAs in cancer & 14.1 & $3.07 \times 10^{-29}$ \\
\hline hsa04115 & p53 signaling pathway & 7.23 & $2.38 \times 10^{-29}$ \\
\hline hsa05205 & Proteoglycans in cancer & 11.57 & $1.63 \times 10^{-27}$ \\
\hline hsa04210 & Apoptosis & 6.69 & $6.13 \times 10^{-26}$ \\
\hline hsa04668 & TNF signaling pathway & 8.32 & $2.89 \times 10^{-25}$ \\
\hline hsa04510 & Focal adhesion & 10.85 & $4.08 \times 10^{-23}$ \\
\hline hsa04380 & Osteoclast differentiation & 8.68 & $1.21 \times 10^{-22}$ \\
\hline hsa04010 & MAPK signaling pathway & 11.75 & $8.86 \times 10^{-22}$ \\
\hline hsa04722 & Neurotrophin signaling pathway & 7.78 & $1.68 \times 10^{-19}$ \\
\hline hsa04012 & ErbB signaling pathway & 6.69 & $2.67 \times 10^{-19}$ \\
\hline hsa04917 & Prolactin signaling pathway & 5.79 & $3.57 \times 10^{-17}$ \\
\hline hsa04914 & Progesterone-mediated oocyte maturation & 6.33 & $3.70 \times 10^{-17}$ \\
\hline hsa04014 & Ras signaling pathway & 9.76 & $3.87 \times 10^{-16}$ \\
\hline hsa04550 & Signaling pathways regulating pluripotency of stem cells & 7.41 & $7.26 \times 10^{-15}$ \\
\hline hsa04919 & Thyroid hormone signaling pathway & 6.69 & $9.79 \times 10^{-15}$ \\
\hline hsa04350 & TGF-beta signaling pathway & 5.79 & $1.28 \times 10^{-14}$ \\
\hline \multicolumn{4}{|c|}{ REACTOME Database } \\
\hline R-HSA-69231 & Cyclin D associated events in G1 & 4.7 & $5.00 \times 10^{-21}$ \\
\hline R-HSA-1538133 & G0 and Early G1 & 3.44 & $1.13 \times 10^{-15}$ \\
\hline R-HSA-69656 & Cyclin A:Cdk2-associated events at $S$ phase entry & 2.35 & $1.10 \times 10$ \\
\hline R-HSA-69273 & Cyclin A/B1 associated events during G2/M transition & 2.71 & $1.42 \times 10$ \\
\hline R-HSA-2173796 & $\begin{array}{c}\text { SMAD2/SMAD3:SMAD4 heterotrimer } \\
\text { regulates transcription }\end{array}$ & 3.07 & $4.22 \times 10$ \\
\hline R-HSA-1257604 & PIP3 activates AKT signaling & 4.34 & $5.16 \times 10^{-9}$ \\
\hline R-HSA-5674400 & Constitutive Signaling by AKT1 E17K in cancer & 2.53 & $4.01 \times 10^{-8}$ \\
\hline R-HSA-2219530 & Constitutive Signaling by Aberrant PI3K in cancer & 3.62 & $6.77 \times 10^{-8}$ \\
\hline R-HSA-69202 & Cyclin E associated events during G1/S transition & 1.99 & $9.93 \times 10^{-8}$ \\
\hline R-HSA-1912408 & Pre-NOTCH Transcription and Translation & 2.53 & $4.36 \times 10^{-7}$ \\
\hline
\end{tabular}

\subsection{Protein-Protein Interaction Analysis}

We evaluated the physical interactions of the members of the consensus list by including the protein interactions described for Homo sapiens from the STRING database [20]. The protein-protein interaction (PPI) generated an osteosarcoma-PPI network (OS-PPI) of 505 nodes from the 553 consensus genes (91.3\%). The node degrees of the 58 pathogenic genes (named as G1 and G2) detected in this network were higher than the non-pathogenic ones (39.05 and 19.25, respectively), showing statistical differences when applying the non-parametric Mann-Whitney $U$-test $(p<0.001)$. Therefore, a higher node degree given by this interaction signifies a greater probability of association with pathogenesis within the prioritized genes.

\subsection{Communality Analysis and Weight of Enriched Pathway}

The communality analysis was carried out using the clique percolation method. The clustering data through the communality analysis was obtained with Cfinder [21], which defined "k-cliques" based on the interaction degree of each node from the OS-PPI network and the extent to which different communities overlapped in said network. The clique percolation method allowed us to detect 14 k-cliques and 86 possible communities with a composition of between 17 and 465 genes. The early minimum in $S^{k}$ variation with respect to k-parameters (Figure 2) revealed that $k=8$ and $k=9$ have similar gene distributions within communities ( $S^{k}$ index 0.719 and 0.609 , respectively). Both k-cliques are suitable for further analysis; however, we chose $k=9$ because it had a better Mean_rank (218.89) 
than $k=8$ (243.95). Moreover, $k=9$ is composed of 13 communities and 245 genes $(44.3 \%$ of the 553 OS genes).

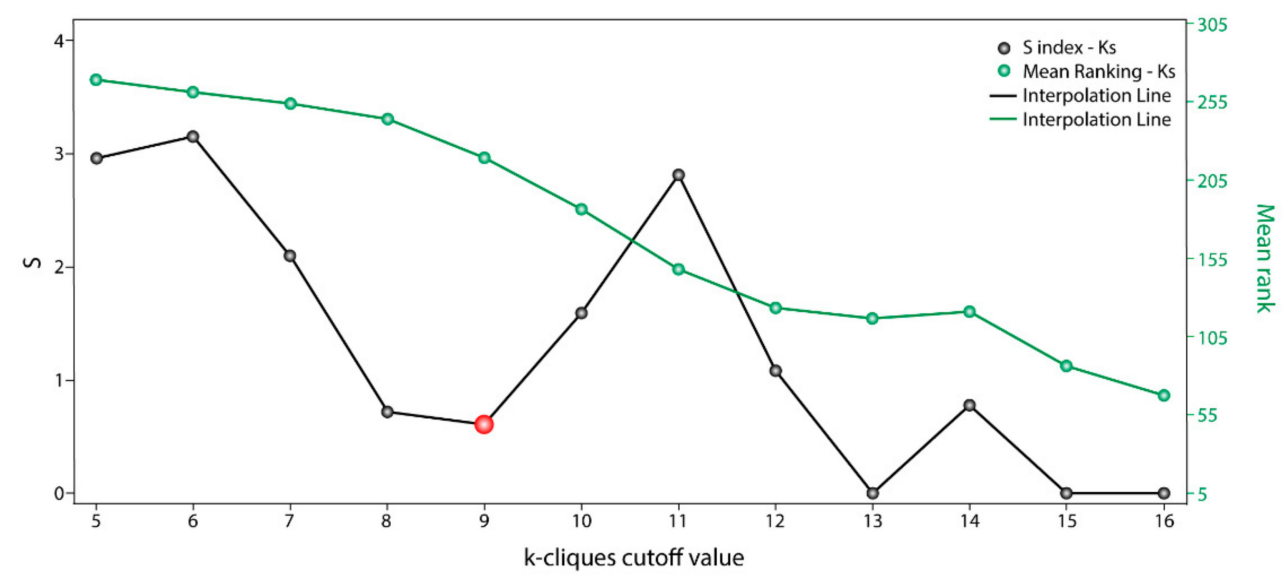

Figure 2. $S^{k}$ scoring with respect to each k-clique cutoff value. Communality analysis by clique percolation method. Values of $S^{k}$ (black points) and mean rankings (green points) with respect to each k-clique cutoff value.

In order to weigh the metabolic pathways obtained in the enrichment analysis, we ranked these terms within each k-clique by means of a pathway enrichment analysis. The pathway enrichment analysis of genes in the 13 communities for $k=9$ (Table S7) is consistent with the results obtained in the enrichment analysis (Table 4). As shown in Table 5, P53, cell cycle, and FOXO continue to hold the top positions and ErbB, TGFB and VEGF improved their statistical significance within this k-clique.

Table 5. Pathways enrichment analysis of $k=9$ communities and their associated weights.

\begin{tabular}{ccc}
\hline Pathway Name & PathScore $_{\mathbf{m}}$ & Community \\
\hline p53 signaling pathway & 0.603 & $2,4,9,10$ \\
Cell cycle & 0.595 & $2,4,7,8,9,13$ \\
FoxO signaling pathway & 0.578 & $2,7,8,10,11,12,13$ \\
Prolactin signaling pathway & 0.574 & $2,8,10,12$ \\
ErbB signaling pathway & 0.565 & $2,10,11,12,13$ \\
Central carbon metabolism in cancer & 0.564 & $2,10,11,12,13$ \\
TGF-beta signaling pathway & 0.553 & $2,6,7,8$ \\
Pathways in cancer & 0.546 & $2,3,4,5,6,7,8,9,10,11$ \\
VEGF signaling pathway & 0.536 & 12,13 \\
Adherens junction & 0.534 & $2,10,11,12$ \\
Proteoglycans in cancer & 0.534 & $2,3,6,7,8,10,11,12$ \\
HIF-1 signaling pathway & 0.532 & $2,10,11,12,13$ \\
Choline metabolism in cancer & 0.526 & $2,5,6,7,8,10,11,12,13$ \\
Thyroid hormone signaling pathway & 0.524 & $2,10,11,12$ \\
TNF signaling pathway & 0.523 & $1,2,3,5,6,7,10,13$ \\
NOD-like receptor signaling pathway & 0.522 & $2,5,8,13$ \\
Osteoclast differentiation & 0.52 & $2,8,13$ \\
Focal adhesion & 0.518 & $2,8,11,12,13$ \\
Progesterone-mediated oocyte maturation & 0.518 & $2,10,11,12,13$ \\
Apoptosis & 0.515 & 2 \\
Neurotrophin signaling pathway & 0.515 & $2,4,5,8,9,10,13$ \\
Fc epsilon RI signaling pathway & 0.514 & $2,5,10,11,12,13$ \\
MicroRNAs in cancer & 0.508 & $2,10,11,12$ \\
mTOR signaling pathway & 0.504 & $2,4,8,9,10,12,13$ \\
B cell receptor signaling pathway & 0.502 & 2,10 \\
\hline & & $2,5,8,10,11,12,13$ \\
\hline
\end{tabular}


To be more selective about which communities would be most relevant within these 13, we used a clustering analysis. The K-means clustering analysis revealed four main community groups (Figure 3). Cluster 1 (Communities 4, 9 and 13) had the highest average values of ConsenScore $e_{i}$ Degree $_{i}$ and PathScore $_{m}$, followed by Cluster 2 (Communities 5, 8 and 10) with regards to ConsenScore ${ }_{i}$ and Degree $_{i}$. Therefore, these six communities were chosen for further analysis.

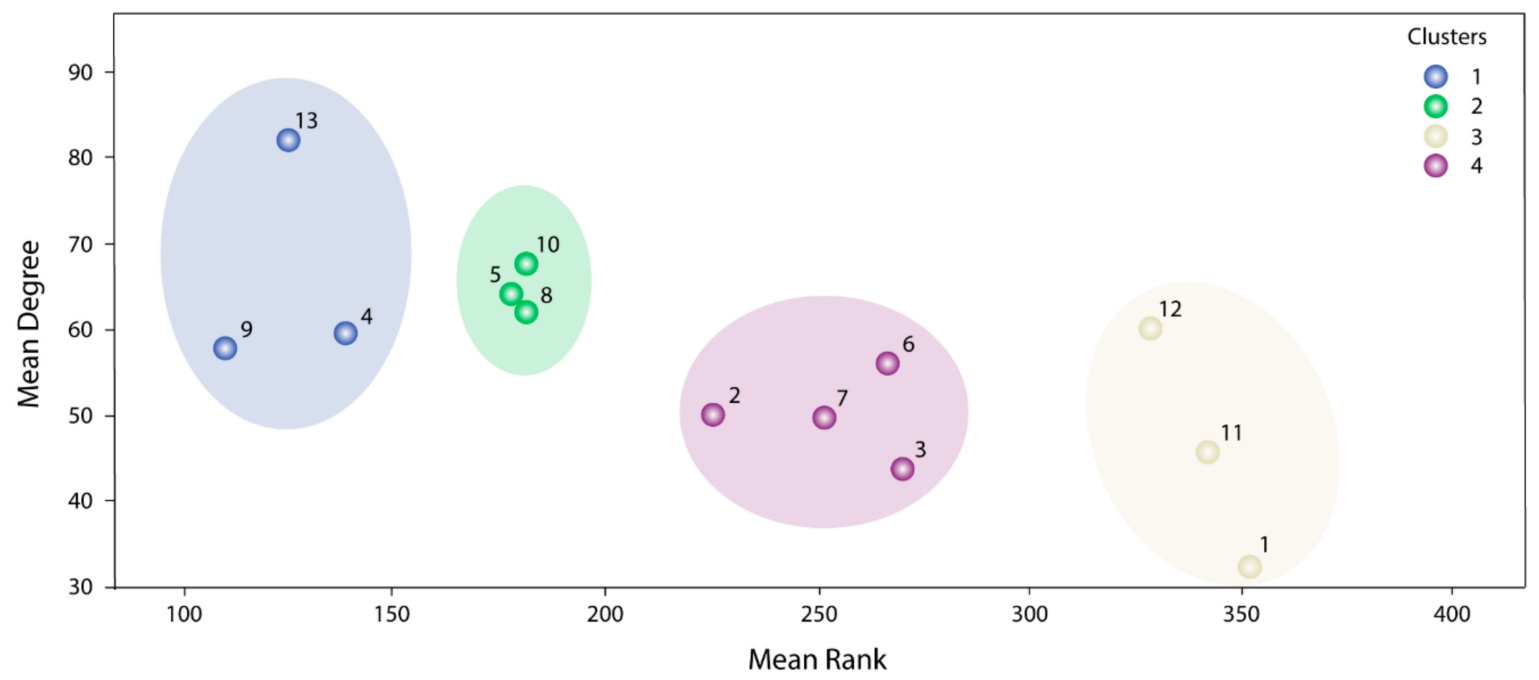

Figure 3. Clustering analysis for the $k=9$ communities. Blue circles represent Cluster 1, purple circles Cluster 2, yellow circles Cluster 3 and purple circles represent Cluster 3.

Communities 4,5,8,9,10, and 13 have groups from 9 to 13 genes and, in total, contain 47 prioritized genes. The genetic distribution among the communities is almost specific and only Communities 4 and 9 present a high similarity (77\%) regarding gene composition (Table 6). Only TP53 is shared in five of the six communities, which denotes its centrality in this prioritization.

Table 6. Gene distribution in the most relevant communities in $k=9$-clique.

\begin{tabular}{|c|c|c|c|c|c|}
\hline Comms & Genes & $\begin{array}{c}\text { Mean } \\
\text { ConsenScore }_{i}\end{array}$ & Mean Degree & $\begin{array}{c}\text { Mean } \\
\text { PathScore }_{m}\end{array}$ & $\begin{array}{c}\text { Pathogenic } \\
\text { Genes/Genes }\end{array}$ \\
\hline 9 & $\begin{array}{c}\text { TP53, ATM, BRCA1, CHEK1, } \\
\text { CDK2, ATR, BRCA2, } \\
\text { RAD51, BLM }\end{array}$ & 0.802 & 57.78 & 0.656 & 0.333 \\
\hline 13 & $\begin{array}{c}\text { TP53, JUN, VEGFA, MYC, } \\
\text { MMP2, BCL2, MMP9, } \\
\text { NFKB1, IL6, FGF2, AKT1, } \\
\text { TGFB1, CDH1 }\end{array}$ & 0.776 & 81.85 & 0.598 & 0.692 \\
\hline 5 & $\begin{array}{c}\text { SMARCB1, HMGB1, KAT2B, } \\
\text { RELA, ARID1A, } \\
\text { NR3C1, SMARCE1 }\end{array}$ & 0.68 & 64 & 0.594 & 0.182 \\
\hline 8 & $\begin{array}{c}\text { NFKB1, SP1, CREBBP, } \\
\text { CEBPB, CEBPD, STAT3, } \\
\text { KLF4, EP300, RELA, } \\
\text { PPARG, TGFB1 }\end{array}$ & 0.675 & 62 & 0.612 & 0.273 \\
\hline 10 & $\begin{array}{c}\text { TP53, VEGFA, EGFR, PTK2, } \\
\text { ERBB2, SHC1, PTEN, } \\
\text { PIK3CA, HRAS, KRAS }\end{array}$ & 0.673 & 67.4 & 0.599 & 0.6 \\
\hline
\end{tabular}

Genes in Communities 8, 10, and 13 are highly relevant for the signaling pathways PI3K/AKT and ERBB/MAPK (PIK3CA, PTK2, HRAS, KRAS, SCH1, AKT). In Community 13, the matrix metalloproteases 
$M M P 2$ and $M M P 2$ are prioritized, which together with $F G F 2$, reflects processes related to cell migration. Since AKT is a central protein in cellular signaling, several downstream effectors are described in Communities 5 and 8. The genes ARID1A, SMARCE1 and SMARCB1, specific to Community 5, are mainly associated with chromatin remodeling.

Given the close metabolic relationship between Communities 5, 8, 10, and 13, it is not surprising that JUN, NFKB1, VEGFA, TGFB1, CREBBP, and RELA are shared among them. However, Communities 4 and 9 are isolated from the rest of the clusters and only have TP53 in common. The genetic composition of both communities is specific to one biological process: DNA repair. ATM, CHEK1, ATR, BRCA1, BRCA2, RAD51, BLM, and MLH1 belong to DNA repair complexes associated with cellular response to DNA damage stimuli, DNA repair, and double-strand break repair via homologous recombination. Altogether, the genetic distribution of these communities is in accordance with the GO analysis obtained from our consensus list (Table 3).

The 47 genes grouped into the six communities defined above represent the most important prioritized members within this study, so we developed a sub-network based on these results (OS-comms network). The centrality index calculated in this sub-network was significantly correlated with the node degree $\left(\right.$ Degree $\left._{i}\right)$ of the same genes in the original OS-PPI network $(r=0.317, p=0.03)$.

\subsection{Gene Validation}

As a validation strategy, we compare our consensus list with the DRIVE project (deep RNAi interrogation of visibility effects in cancer) [22] and with the cancer-focused protein-protein interaction network (OncoPPI) [23] data. The data generated by the DRIVE project described $83.5 \%$ of our 553 consensus genes (Table S8). Of these 461 genes, 20 were determined as essential, 70 as active and 371 as inert. On the other hand, the OncoPPI network recognized 92 of our prioritized genes (16.6\%) and its centrality index showed a significant correlation with the same gene in our OS-PPI network $(r=0.445$, $p<0.001$ ) (Table S9).

As shown in Figure 4A, both DRIVE and OncoPPI genes are present in the OS-comms network. From the DRIVE analysis, BRCA1 and RAD51 were identified as essential and ATR, CDK2, CDK4, CHEK1, SMARCB1, SMARCE1, RELA, AKT1, MYC, HRAS as active. On the other hand, 17 OncoPPI genes ( $36.18 \%$ of 47 in OS-comms network) were present in this network. Upon correlating the centrality indices between the OncoPPI network and the OS-comms network, we obtained a statistical correlation $(r=0.512, p=0.036)$.

We can notice that in Figure 4B, several prioritized genes are actually transcription factors (TFs). Because of this, we chose to perform a second prioritization focused only on TFs and without using PPI networks. The PPI could bias toward physical interactions and reduce the relevance of regulatory mechanism, as presented in TFs. We identified 125 TFs from the initial 553 genes already prioritized. The TFscore $i$ was evaluated for all TFs (Table S2). The top 20 more relevant TFs are TP53, E2F1, JUN, RUNX2, FLI1, YY1, HIF1A, MYC, TP63, ESR1, WT1, E2F4, ATF2, NFKB1, AR, SP1, STAT1, ERG, CEBPB, TFAP2A.

From the $125 \mathrm{TFs}, 4 \%$ were identified as essential and $9.1 \%$ as active when compared to DRIVE genes. Additionally, 19 TFs were present in the OncoPPI network. Regarding community analysis, $27.6 \%$ were TFs and were mainly present within Communities 5, 8 and 13 (Figure 4B). 
A

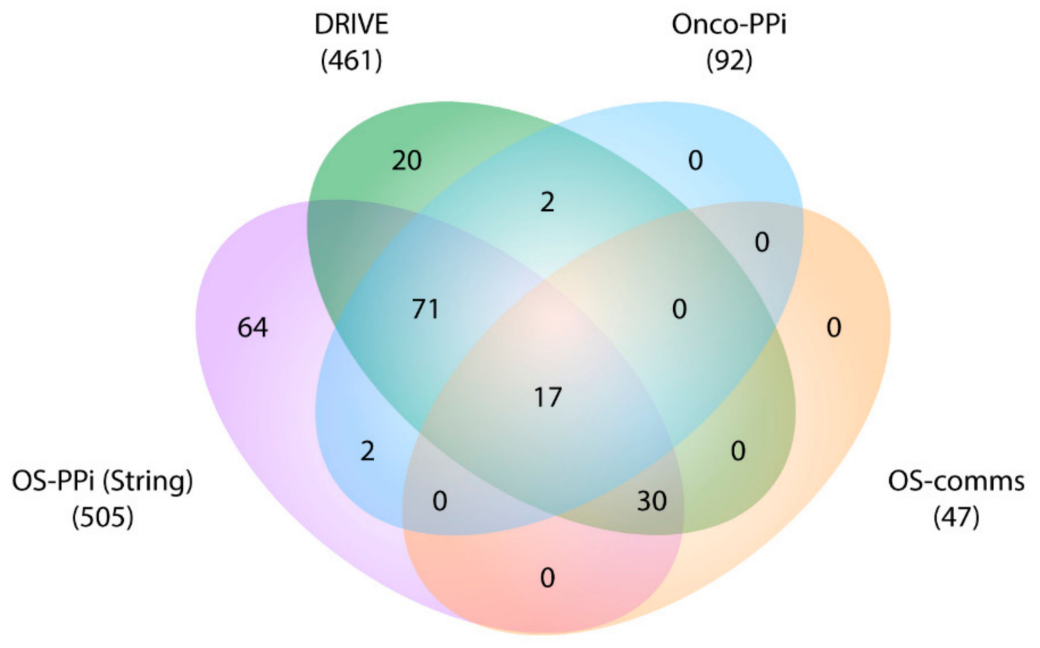

B

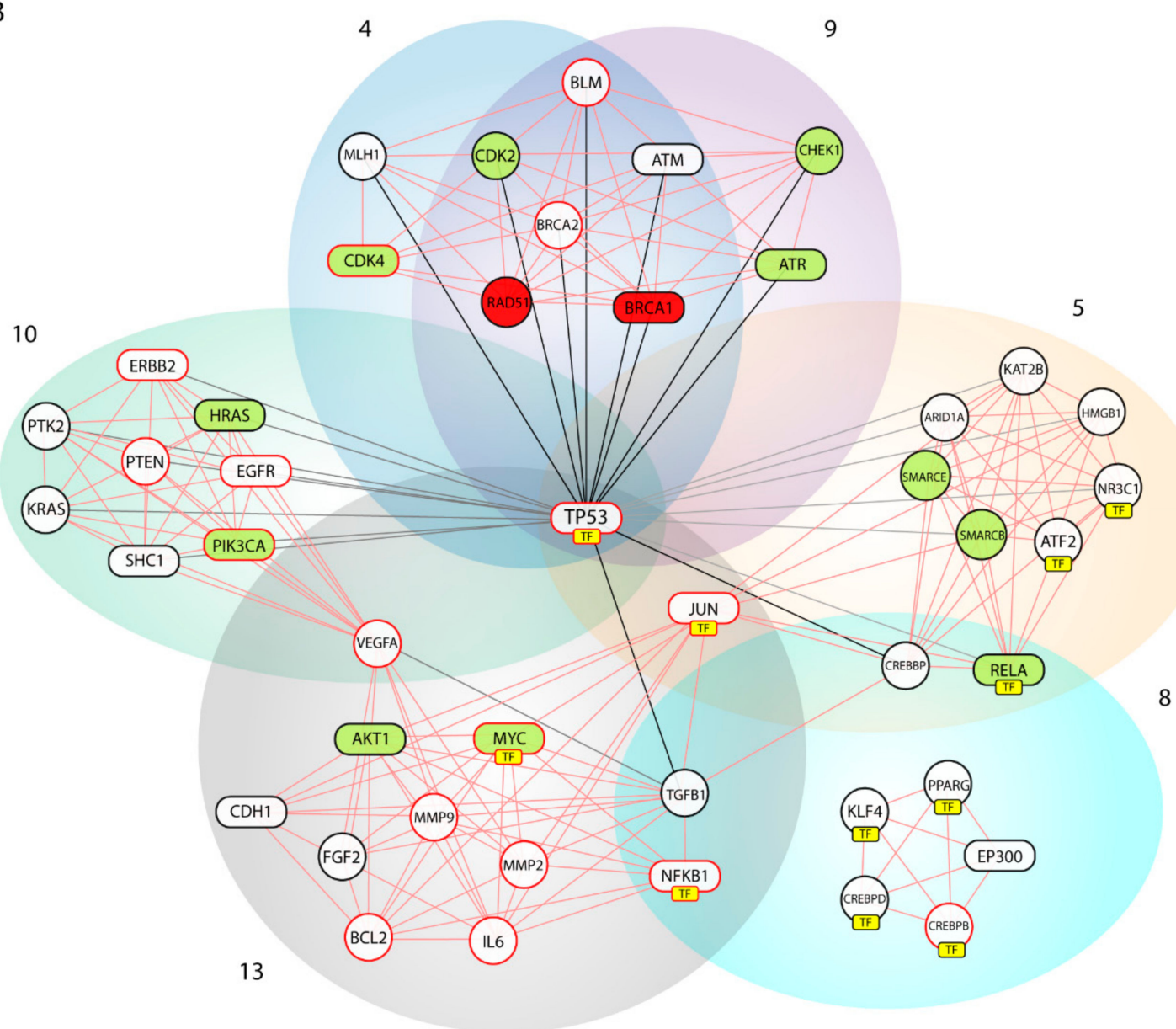

Figure 4. Gene validation and network analysis of the $k=9$-clique. (A) Comparison of prioritized genes from STRING (OS-PPI), DRIVE Project, OncoPPi network, and Cfinder analysis; (B) Network analysis from Communities 9, 13, 4, 5 8, and 10 (OS-comms network). Red and green painted nodes are defined as essential and active genes, respectively, based on the results from the DRIVE project. Nodes enclosed in rectangles belong to the analyzed OncoPPI network. Nodes with red borders are members of G1 and G2. Yellow boxes (TF) point to nodes identified as transcription factors. 


\section{Discussion}

As shown in Table 1, the detection rate of our consensus prioritization strategy was higher than all the bioinformatics tools employed in this analysis. Moreover, the mean rank of the pathogenic genes detected in the top $1 \%$ of the list was 49.3. Table 2 indicates that, on average, the 45 G1-G2 genes were located in the top 50 positions. These results confirm that this methodology does indeed improve the detection and prioritization of pathogenic genes, as had been previously described in other pathologies [24,25].

As a first approach, the prioritization strategy resulted in a consensus list of 553 genes and the 10 top-ranked genes were TP53, RB1, CHEK2, RUNX2, E2F1, MDM2, CDKN1A, JUN, CCNA2 and CDKN2A. TP53, RB1, CHEK2, and MDM2 were ranked in 1st, 2nd, 3rd, and 6th positions, respectively, and also the arrangement of the pathogenic genes in this list shows a distribution in the top positions. So far, the gene ranking along this prioritization reflects a proper gene weighting based mainly on this consensus strategy. These genes had been previously described in OS pathogenesis. Early studies focused on the molecular biology of OS were carried out on individuals with familial syndromes, which predisposed them to this tumor. Germline inactivation of RB1 and TP53 were initially described in patients with hereditary retinoblastoma and Li-Fraumeni syndrome, respectively [26,27], and subsequently in sporadic sarcomas $[28,29]$. Given that these two suppressors are central proteins in controlling the cell cycle, later studies briefly described many others that interacted with them. Mouse double minute 2 (MDM2), for example, is a protein that binds to RB1 and inactivates TP53 [30]. Its amplification is an event that occurs in primary OS (3-25\%) and it is overexpressed in metastases and recurrences [31,32]. CHEK2 is another protein that is part of a DNA damage checkpoint, works as a stabilizer of TP53, and shows a $7 \%$ frequency of mutations in OS patients [33,34].

The biological processes derived from the GO analysis of the 553 genes describe TP53 as a principal signal transducer that mediates processes associated with cell cycle, DNA damage response, DNA replication and intrinsic/extrinsic apoptotic signaling regulation. Additionally, more specific biological processes were described, for instance, fibroblast proliferation, osteoblast differentiation and development, and mesenchymal cell proliferation and transition. In accordance with our results, previous studies have identified similar biological processes related to OS, where the following are considered OS-associated terms: cell cycle regulation (mainly mediated by RB1 and TP53), osteoblast differentiation (mediated by RUNX2), DNA damage, stress response, epigenetic processes, mitosis, cell motility functions, and members involved in OS cell proliferation (weighting NFKB signaling, NFKBIE, and RELA members) [3,35-37]. Taken together, these processes suggest that the consensus list is evidence of the genes associated with osteogenesis, cell differentiation, and transition to bone cell types. In addition, the terms derived from the pathway enrichment analysis (Table 4) are in accordance with these biological processes.

The information used by STRING allowed us to define the degree of physical interaction of the consensus list members and calculate their centrality index. This centrality index was used as a variable to evidence the contribution rate of the pathogenic genes to a common biological purpose. Thus, the greater the centrality for a node within the OS-PPI network, the greater the probability of its contributing to pathogenesis. This association was validated by analyzing the genes defined as pathogenic (G1-G2), in which significant differences were observed in comparison with the rest of the consensus genes $(p<0.0001)$. The centrality index calculated from the 503 nodes included in the protein-protein interaction network determined TP53 as the most central node, followed by AKT1, $M Y C$, JUN, EP300, CREBBP, CCND1, CDKN1A, STAT3, and RB1. Furthermore, this degree allowed for the definition of more specific clusters and prioritization of gene communities associated with OS pathogenesis. Thus, k-9 was determined as the clique with the best gene distribution among all the resulting communities ( $S^{k}$ index 0.719 ) and Communities $4,5,8,9,10$, and 13 as the most important groups of genes within our study.

The pathway enrichment analysis for the $k=9$-clique results in, almost in its entirety, the same terms obtained from the initial consensus list. This confirms that the gene filtered through the communality 
analysis comprised almost the same biological processes. Considering the PathScore $m$ (Table 5), the P53 signaling pathway and cell cycle are in the top positions. FOXO also increases its significance in this enrichment analysis. In different cancer types, PI3K/AKT, Ras-MEK-ERK, IKK, and AMPK are the most important signaling pathways interacting with FOXO [38]. The gain of function of P13K and RAS, or PTEN disruption, are oncogenic events that promote a loss of function in the Forkhead Box transcription factors $(F O X O)$ [39]. Interestingly, loss of its expression promotes impaired osteogenic differentiation, suggesting that FOXO1 is involved in osteoblastogenesis and osteoclastogenesis [40-42]. Moreover, FOXO members have an important role in cell fate decision, via triggering the expression of death receptor ligands like FASLG, TNF apoptosis ligand, and some BCL-2 family members (BCL2L1, $B N I P 3, B C L 2 L 11$ ) [43-46]. FOXO expression in OS tumors is low or even lacking altogether, leading to tumor progression and cell cycle arrest [47]. The fact that FOXO enhances its weight within our enrichment analysis demonstrates its importance as a signaling pathway in the pathogenesis of OS. Furthermore, the close relationship between the FOXO signaling pathway and cell cycle, events of osteoclast differentiation and apoptosis via the TNF signaling pathway, is evidenced in the pathway enrichment analysis applied to the consensus list and the $k=9$ clique.

Our consensus strategy seeks to specify a group of genes that describe the molecular etiology of OS. In this sense, the use of all the strategies previously described prioritizes to a great extent the 47 genes arranged in Communities 4, 5, 8, 9, 10, and 13. From these six communities, BRCA1, AKT1, ATR, CDK4, HRAS, MYC, PIK3CA, RELA, STAT3 are genes validated by DRIVE and Onco-PPI (19.1\%), RAD51, CDK2, CHEK1, SMARCB1, SMARCE1 are validated only by DRIVE (10.6\%), and ATM, CDH1, EGFR, EP300, ERBB2, JUN, NFKB1, SHC1, TP53, SP1 by Onco-PPI (21.3\%). The sub-network generated from these communities (OS-comms network) reflects closely interrelated genes at the cellular interaction level (Figure 4B) and also groups of genes immersed in important oncological processes. Tamborero et al. [48], from exome sequencing data of 3205 tumors in the Cancer Genome Atlas (TCGA) research network, proposed 291 high-confidence cancer driver genes acting on 12 different cancer types. Although in this study, data from samples of bone tumors were not taken into account, their results showed the members of the PI3K signaling pathway as central onco-drivers, ATR-BRCA1 as regulatory nodes of repair processes associated with TP53, CHEK1 and AKT as the main regulators of cell cycle in function of CDK1A, and CDK1B and activators for downstream pathways such as FOXO. This experimental data support our findings, where PIK3CA, AKT1, PTEN, HRAS and SHC1 were nodes highly connected within our OS-comms network. Nodes that connect to Communities 10 and 13 describe genes representative of our weighted tumorigenic pathways, PI3K/AKT and MAPK/ERK.

The findings reported here suggest that PI3K/AKT and MAPK/ERK are the main signaling pathways deregulated for OS. Several reports have shown that these pathways are responsible for controlling cellular processes related to proliferation, growth, differentiation, and apoptosis $[49,50]$. In fact, the Ras/Raf/MEK/ERK pathway is hyperactivated in 30\% of human cancers [51] and nearly $67 \%$ of OS shows aberrant ERK activation [52]. The extra cellular-signal-regulated kinases (ERK) promote cell proliferation, cell survival, and metastasis, particularly by its upstream activation from EGFR and the G protein-coupled receptor Ras [53]. The presence of SHC1, EGFR, HRAS, PIK3CA, ERBB2 within Community 10 support this scenario for OS. In addition, the high connectivity of the matrix metalloproteases, MMP2 and MMP9, in Community 13 suggests a metastasis event in the function of these signaling pathways.

Although the invasion of tumor cells is a general characteristic in carcinogenesis, metastasis to the lung is one of the main characteristics in patients with OS and one of the major causes of mortality [54,55], so this event is a hallmark for this sarcoma. Pathogenic events, including cellular detachment from primary tumors, matrix remodeling and invasion from tumor cells, angiogenesis, vascular dissemination, and proliferation at new sites, are involved in tumor metastasis [56,57]. Upstream regulators of MAP/ERK signaling such as IL6, VEGFA, and FGFR1 demonstrate an important role in this process [58-62] and are prioritized in our results. In addition, Community 13 shows the 
MMP2 and MMP9 genes with a high centrality index. A high expression of MMP9 was observed in metastatic OS samples [63,64], leading to speculation that this metalloproteinase can promote cell migration and invasion in OS by degradation components of the extracellular matrix. This evidence suggests that $M M P 2$ and $M M P 9$, together with upstream regulators of MAP/ERK signaling such as IL6, FGF2, VEGFA, EGFR and ERBB2, are pathogenic nodes dependent on the centrality of PI3K/AKT and MAPK/ERK. This finding could be related to aspects of invasiveness and prognosis, mainly in tumors that present deregulation in these two signaling pathways.

In addition to evidencing the previous findings, Communities 4, 5 and 9 include genes widely described in processes of homologous recombination (HR), base excision repair, and chromatin modification. Cells DNA damage response principally involves maintaining chromosome integrity and genome stability and implies recognition of DNA lesions, followed by an activation of the checkpoints in the cell cycle that promotes cellular signaling cascades related to DNA repair. While the ATM-CHEK2 pathway is responsible for the initiation of cellular responses to double-strand breaks $[65,66]$, ATR-CHEK1 responds to DNA replication stress by means of the phosphorylation of several substrates in response to agents such as UV and X-ray among others [67]. ATM, ATR, and CHEK1 show a high centrality index in the OS-comms network, interacting in addition to BRCA1 and RAD51, described as essential genes, and with the cyclin-dependent kinases, $C D K 2$ and CDK4, described as active ones according to the DRIVE validation. Checkpoint activation by ATM mainly controls G1/S, whereas ATM and ATR contribute to establishing and maintaining the $S$ and G2/M checkpoints [68]. Either by activation of ATR-CHEK1 or ATM-CHEK2, DNA damage signaling promotes inhibition of CDK activity and therefore the activation of G1/S, intra-S, and G2/M checkpoints [69]. Consequently, it is likely that such nodes associated with DNA repair, such as ATM, ATR, CHEK1, BLM, RAD51 and MLH1 (as shown in our pathway enrichment analysis), together with those previously described (BRCA1 and $B R C A 2)$ from exome sequencing [70], have important implications regarding the deregulation of the cell cycle evidenced in OS.

While it is true that the nodes described for Communities 4 and 9 are mainly related to repair and cell cycle control events, the HR repair complex is involved in a hallmark event for sarcomas, such as alternative telomere maintenance (ALT). Several molecular details of this mechanism still remain unknown; however, two distinctive telomere phenotypes are described for ALT in human telomerase-negative cells (ALT cells) such as long and heterogeneous telomere DNA and promyelocytic leukemia (PML) body [71], together forming the ALT-associated promyelocytic leukemia body (APB). The PML body is a nuclear made up of proteins which form amongst the chromatin and is related to a wide range of cellular processes including tumors formation, cellular senescence, and DNA repair [72,73]. Numerous lines of evidence strongly suggest that the ALT pathway is dependent on HR since several proteins involved in DNA double-strand break (DSB) are localized at APBs [74-77]. It is significant that proteins localized at APBs, such as PML, DNA helicases of the RecQ family (BLM, WRN and RECQL4), RAD51 and RAD52 (a member of the MNR complex), rank highly in our prioritization. In this sense, the members belonging to HR complexes are described as repair complexes in response to DNA damage. They are relevant to the pathogenesis of the OS, not only as factors immersed in cell cycle control, as previously discussed, but also because they are involved in processes of chromosome stability given by telomere maintenance [78-81]. Consistent with the literature, where bone tumors are termed as highly heterogeneous, highly mutable, and genetically unstable, members described in Communities 4 and 9 (TP53, ATM, ATR, CHEK1, BLM, BRCA1, BRCA2, RAD51, MLH1, CDK2, CDK4) explain many of these key features within OS, and can also be associated with important clinical characteristics such as tumor aggressiveness, metastasis, and poor survival.

The use of the GTRD database allowed us to define the frequency of interaction of each TF with the 553 prioritized genes. It is worth noticing that more than half of the prioritized factors $(103,82.4 \%)$ interacted with more than half of all genes at the same time. This suggests that more than $80 \%$ of the genes defined as TFs actively regulated the genes associated with the pathogenesis of OS. The weight given to each one of these TFs through interaction analysis places the following genes on the top 
positions: TP53, E2F1, JUN, RUNX2, FLI1, YY1, HIF1A, MYC, TP63, ESR1, WT1, E2F4, ATF2, NFKB1, $A R, S P 1, S T A T 1, E R G, C E B P B$, and TFAP2A. When compared to total prioritization, genes E2F1, JUN, RUNX2, FLI1, YY1, HIF1A, MYC, TP63, ESR1, WT1, E2F4, ATF2, and NFKB1 significantly improved their ranking. During the G1 phase of the cell cycle, RB1 suppresses the function of the E2F1, E2F2, and E2F3 TFs. Sequential hypo phosphorylation of RB1 by cyclin-dependent kinases, CDK4 and CDK6, and CDK2, led in the release of E2F and transcription of genes necessary for cell cycle progression, including cyclins A, D, and E [82]. The improved score of these TFs suggests that these deregulation events in the cell cycle are basal within the pathogenesis of the OS. Although this scenario is common for all types of cancer, a deeper study of the E2F1 and E2F4 genes, and depending on those prioritized in Communities 4 and 9 along with TP53, would be necessary to define driver proteins in OS tumors.

We identified TP53, JUN, MYC, ATF2, NFKB1, SP1, CEBPB, STAT3, KLF4, RELA, NR3C1, CEBPD, and PPARG as TFs (13 or the 47 nodes) in the OS-comms network. The new ranking calculated for each of them improved significantly when compared to the ranking of all OS genes (Table S2). This suggests that their degree of regulation within this network is very significant and shows evidence of its importance as regulatory proteins within each prioritized cluster.

TFs were grouped over Communities 5, 8 and 13. With TP53 as the central node, JUN and MYC are key factors in the pathogenesis of the OS that regulate signaling associated with the pathogenic pathways PI3K/AKT and MAPK/ERK. Furthermore, the prioritization of TFs evidenced NFKB1 as a central node in these three communities. Nuclear factor-kappa B1 (NF $\kappa B 1)$ is a pleiotropic transcription factor that contributes to tumorigenesis in many types of cancer. It works as a key regulator of a variety of genes implicated in many biological events including cell survival, differentiation, apoptosis, and autophagy [83]. When observing the OS-comms network, the high degree interaction of $A K T$ with respect to JUN-MYC, TGFB1, NFKB1, and BCL2 suggests this cluster as an important group in the OS pathogenesis. GO terms listed in Table 3 are in accordance with these findings since its activation promotes many types of downstream signaling including osteoblast differentiation via TGFB1 and NFK1 or apoptosis via BCL2 $[84,85]$.

In conclusion, the use of a consensus strategy proved to be efficient when specifying a broad list of genes obtained from several bioinformatics prioritization tools. In addition, the combination of these strategies with a network enrichment analysis allowed us to show not only real interactions between specific genes but also to define internal interactions that explained cellular events associated with OS pathogenesis. Our results validate several studies that describe the signaling pathways PI3K/AKT and MAPK/ERK as oncological for OS. Nevertheless, given its centrality at the cellular signaling level, its deregulation can influence downstream specific pathways, such as FOXO, and promote tumorigenic scenarios like osteoblast undifferentiation via TGFB1 and NFK1, apoptosis via BCL2, and migration and metastasis mediated mainly by MMP2 and MMP9.

What is more, the gene composition of Communities 4 and 9, and more specifically to their ATM, $A T R, C H E K 1$, and RAD51 genes, suggest that the HR repair complex is an important group of genes within the pathogenesis of the OS. Its deregulation can influence tumorigenic events characteristic of this sarcoma as generalized disruption in the cell cycle and ALT mechanisms. Hence, it is necessary to experimentally validate these results, taking into account not only the patient's age group but also genetic factors that can influence the molecular behavior of these bone tumors, such as racial and ethnic factors. It should also be interesting to study genetic variants of the transcription factors identified and their relationship with possible disease prevalence.

\section{Materials and Methods}

\subsection{Prioritization Methods and Consensus Strategy}

The bioinformatics methods used in this study were for gene-disease prioritization Biograph [86], Cipher [87], DisGeNET [88], Génie [89], GLAD4U [90], Guildify [91], Phenolizer [92], PolySearch [93], and SNPs3D [94]. We chose these nine bioinformatics methods because (1) they are fully available 
on web service platforms and (2) they only required the disease name (or OMIN code, 259,500 for OS) for gene prioritization. With the disease name and/or the OMIM code, a list of prioritized genes was obtained from each method. Each of these methods follows several different strategies for gene prioritization, and as a final output, they also provide different scores for each gene.

The strategy applied to integrate the gene scores obtained in each independent method is similar to that previously described $[24,25]$. Thus, we normalized each gene (denoted as $i$ ) from the ranked list obtained from each method (denoted as $j)\left(\right.$ GeneN $_{i, j}$ which means, the normalized score of the gene " $i$ " in the method " $j$ "). The final score by gene (ConsenScore $i$ ) was considered as the average normalized score and the number of methods which predict the gene (denoted as $n_{i}$ ) are

$$
\text { ConsenScore }_{i}=\sqrt{\left(\frac{\left(n_{i}-1\right)}{9-1}\right)\left(\frac{1}{j} \sum_{j} \mathrm{GeneN}_{i, j}\right)}
$$

This equation refers to the geometric mean between the average score of each gene derived from each method, and the normalized score according to the number of methods that predict the association of the gene and the disease. This consensus approach will lead to a big final list of genes ranked according to the ConsenScore $i$. In order to reduce this list, we needed to follow some rational strategy.

From a manual observation and curation of the scientific literature, we create a list of genes that are highly probable to be involved in OS pathogenesis (Table S1). For this, we took into consideration pathogenic OS genes defined by a literature review of two types of studies: meta-analysis, based on publications and case reports for OS patients (named as G1 genes), and gene description in animal models and OS cell lines (named as G2 genes). Thereby, we identified 75 pathogenic OS genes from the available literature, of which 47 were classified as G1 and 41 as G2. These manually curated genes were used for (1) validation of the prioritized genes (and networks) and (2) to reduce the initial list of consensus genes.

The pathogenic OS genes (defined as G1 and G2 in Table S1) were used to calculate $I_{i}=\frac{T P_{i}}{F P_{i}+1}$ ConsenScore $_{i}$, where TP and FP are the true and false positive values (up to the ranking value of the gene $i$ ), respectively. According to that which has been previously described [24,25], the maximum value of $I_{i}$ can be taken as the maximum compromise between the TP and FP rates compensated with the ranking index of each gene. The ranking (" $\mathrm{i}$ "), at which " $\mathrm{I}$ " _ $\mathrm{i}$ " is maximal, will represent a rational cut-off for the consensus list.

We applied another prioritization methodology to demonstrate the degree of interaction of all transcription factors in our consensus genes. We used the "The Human Transcription Factors" database [95] to identify the TFs from the 553 initially prioritized genes. The second prioritization of

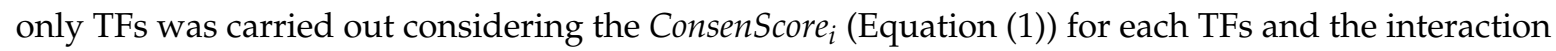
degree of each TF using the information described in the GTRD (Gene Transcription Regulation Database) [96]. This database contains experimental information from ChIP-seq experiments of TF binding sites. Data were systematically collected and uniformly processed using a special workflow (pipeline) for a BioUML platform (http://www.biouml.org). By inspecting all the target genes described for Homo sapiens, we downloaded the information of all the genes defined as TF and all the genes or +/$5000 \mathrm{bp}$ that contain a GTRD meta cluster for this TF.

Thus, the TFscore $_{i}$ was calculated as

$$
\text { TFscore }_{i}=\sqrt{\left(\frac{\left(t_{i}-1\right)}{553-1}\right) \text { ConsenScore }_{i}}
$$

where $t_{i}$ is the number of genes that are regulated by the transcription factor " $i$ ". The general conception is that a transcription factor will be more relevant if it has a higher value in the consensus score and regulate many of the prioritized genes. 


\subsection{Protein-Protein Interaction Network Analysis}

The protein interactions of the members of the consensus list were revised from the STRING database, only taking into consideration interactions with a confidence cut-off of 0.9. With this information, we generated a OS-PPI network with zero node addition. Network visualization and analysis were carried out through the Cytoscape software [97].

\subsection{Communality and Pathway Enrichment Analysis}

The communality analysis on OS-PPI was carried out using the clique percolation method with Cfinder [21]. The communality analysis provides a topology description of the network including the location of highly connected sub-graphs (cliques) and/or overlapping modules that usually correspond with relevant biological information. The selection of the value "k-cliques" $(k=1,2,3 \ldots \mathrm{n})$ will affect the number of community and also the number of genes in each community. In general, higher values of k-cliques imply few communities while lower values lead to many communities. In the OS-PPI network, both extremes (too small or too high k-cliques values) result in an unbalanced distribution of the genes across communities. This means some of the communities will have a big amount of genes while others will have a very small number.

In order to determine the best k-clique in the communality analysis, we used the index " $S$ " [24,25]: $S^{k}=\frac{\mid \text { mean }\left(N_{g}^{k}\right)-\text { median }\left(N_{g}^{k} \mid\right.}{N_{c}^{k}}$, where $N_{g}^{k}$ and $N_{c}^{k}$ are the number of genes in each community and the number of communities for a defined k-clique cut-off value. If the distribution of genes across communities is close to a Gaussian distribution, or constant, $S^{k}$ will tend toward 0. Once $\mathrm{k}$ is defined in k-clique, a number of communities will be identified.

Additionally, we applied the partitional algorithm K-means in order to define our best communities within a k-clique. The variables used for the clustering were the means of ConsenScore $e_{i}$, Degree $_{i}$, and PathScore $_{m}$ for each community within the k-clique. The Degree $_{i}$ variable refers to the node's degree centrality index calculated for each gene from the OS-PPI network and the PathScore $m$ is outlined below. From communities selected in this clustering, we created a sub-network to visualize the interactions of all the members of the chosen communities.

For the pathway enrichment analysis, we used a PathRankScore ${ }_{m}$ PathGeneScore $_{m}$, and PathScore $_{m}$ as described previously [24]: (1) Each community " $k$ " was weighted as $W_{k}=\sum$ ConsenScore ${ }_{i}^{k} / N_{k}$, where ConsenScore ${ }_{i}^{k}$ is the ConsenScore $e_{i}$ of the gene " $i$ " in the community " $k$ " and $N_{k}$ is the number of communities; (2) Each pathway " $m$ " was weighted as PathRankScore ${ }_{m}=\sum W_{k}^{m} / N_{k}^{m}$, where $W_{k}^{m}$ is the weight $\left(W_{k}\right)$ of each community connected with the pathway " $m$ " and $N_{k}^{m}$ is the number of communities connected with the pathway " $m$ ", and (3) A second weight to the pathway " $m$ ", PathGeneScore $m$, considered all the genes included in each pathway: PathGeneScore $m=\sqrt{\text { ConsenScore }_{i}^{m} \frac{n_{m}}{N_{m}}}$, where $N_{m}$ is the total number of genes in the pathway " $m$ ", while $n_{m}$ is the number of those genes that are also found in the protein-protein interaction network. The average of the ConsenScore $i$ of all genes presents in the pathway " $m$ " is $\left\langle\right.$ ConsenScore $\left.i_{i}^{m}\right\rangle$. The geometrical mean between PathGeneScore $m$ and the normalized PathRankScore $_{m}$ refers to the final score associated with the pathway " $m$ " (PathScore $\left.{ }_{m}\right)$.

\subsection{Gene Validation with the OncoPPi OS Network and the DRIVE Project}

Besides the genes in the G1 and G2 groups, we also used the information in the DRIVE project. It is a project that describes a comprehensive mapping of cancer genes obtained from a larger-scale gene knockdown experiment in 398 cancer cell lines. We filtrated the results of eight cell lines, all of which had pathological annotations related to bone cancer (A673, SAOS2, SJSA1, SKES1, SKNMC, SW1353, TC71, and U2OS). Subsequently, all essential genes that showed a Sensitivity Value of $\leq-3$ in $>50 \%$ of the chosen cell lines, active genes that showed values of $\leq-3$ in $1-49 \%$, and inert ones showed values of $\leq-3$ for $0 \%$ of cancer cells [22] were compared with our results. 
Additionally, from Onco-PPI Portal (http://oncoppi.emory.edu/) [23], a cancer-focused protein-protein interaction network was generated by only considering the interactions described for bone tumor types (labeled as OncoPPI). This network was comprised of 171 genes and 442 interactions. The Spearman correlation of Degree $_{i}$ between the OncoPPI, OS-PPI, and the sub-network from the identified communities were calculated.

Supplementary Materials: Supplementary Materials can be found at http://www.mdpi.com/1422-0067/21/3/1053/ s1. Table S1. Description of pathogenic OS genes. Table S2. Consensus OS gene list. Table S3. Biological processes by enrichment analysis in OS consensus gene list. Table S4. Biological processes of the consensus gene list using Revigo. Table S5. The enrichment analysis of the KEGG pathways of the consensus gene list. Table S6. The enrichment analysis of the Reactome pathways of the consensus gene list. Table S7. Pathway enrichment analysis of $k=9$ of communities and their associated weights. Table S8. Classification of essential, active and inert genes based on the DRIVE project. Table S9. OncoPPi nodes present in the OS integrated network.

Author Contributions: E.T. and A.C.-A. conceived the project and wrote the manuscript. E.T. designed the algorithm. A.C.-A. and A.L.-C. implemented the algorithm and performed the data analysis. G.J.-K., C.P.-y.-M. and Y.P.-C. made substantial contributions in the discussion of the article. C.R.M., H.G.-D. and A.P. helped with study design and edited the manuscript. All authors have read and agreed to the published version of the manuscript.

Funding: This research was funded by "Collaborative Project in Genomic Data Integration (CICLOGEN)", grant number PI17/01826, "Consolidation and Structuring of Competitive Research Units-Competitive Reference Groups", grant number ED431C 2018/49 and "Accreditation, Structuring, and Improvement of Consolidated Research Units and Singular Centers", grant number ED431G/01, funded by the Ministry of Education, University and Vocational Training of the Xunta de Galicia endowed with EU FEDER funds.

Acknowledgments: This work was supported by Universidad de Las Américas (Quito, Ecuador), Hospital de Especialidades Eugenio Espejo (Quito, Ecuador), University of Coruna (Coruña, Spain) and University of the Basque Country (Bilbao, Spain).

Conflicts of Interest: The authors declare no conflict of interest. The funders had no role in the design of the study; in the collection, analyses, or interpretation of data; in the writing of the manuscript, or in the decision to publish the results.

\section{Abbreviations}

OS

TF

GO

PPI

OS-PPI

OS-comms network

OncoPPI

HR

ALT

\author{
Osteosarcoma \\ Transcription factor \\ Gene ontology \\ Protein-protein interaction \\ Osteosarcoma protein-protein interaction network \\ Sub-network based on the communality analysis \\ Protein-protein interaction network obtained from \\ the DRIVE project \\ Homologous recombination \\ Alternative telomere maintenance
}

\section{References}

1. Man, T.K.; Lu, X.Y.; Jaeweon, K.; Perlaky, L.; Harris, C.P.; Shah, S.; Ladanyi, M.; Gorlick, R.; Lau, C.C.; Rao, P.H. Genome-wide array comparative genomic hybridization analysis reveals distinct amplifications in osteosarcoma. BMC Cancer 2004, 4, 45. [CrossRef] [PubMed]

2. Savage, S.A.; Mirabello, L.; Wang, Z.; Gastier-Foster, J.M.; Gorlick, R.; Khanna, C.; Flanagan, A.M.; Tirabosco, R.; Andrulis, I.L.; Wunder, J.S.; et al. Genome-wide association study identifies two susceptibility loci for osteosarcoma. Nat. Genet. 2013, 45, 799-803. [CrossRef] [PubMed]

3. Kuijjer, M.L.; Hogendoorn, P.C.; Cleton-Jansen, A.M. Genome-wide analyses on high-grade osteosarcoma: Making sense of a genomically most unstable tumor. Int. J. Cancer 2013, 133, 2512-2521. [CrossRef] [PubMed]

4. Groisberg, R.; Roszik, J.; Conley, A.; Patel, S.R.; Subbiah, V. The Role of Next-Generation Sequencing in Sarcomas: Evolution From Light Microscope to Molecular Microscope. Curr. Oncol. Rep. 2017, $19,78$. [CrossRef]

5. Cote, G.M.; He, J.; Choy, E. Next-Generation Sequencing for Patients with Sarcoma: A Single Center Experience. Oncologist 2018, 23, 234-242. [CrossRef] 
6. Joseph, C.G.; Hwang, H.; Jiao, Y.; Wood, L.D.; Kinde, I.; Wu, J.; Mandahl, N.; Luo, J.; Hruban, R.H.; Diaz, L.A., Jr.; et al. Exomic analysis of myxoid liposarcomas, synovial sarcomas, and osteosarcomas. Genes Chromosom. Cancer 2014, 53, 15-24. [CrossRef]

7. Bousquet, M.; Noirot, C.; Accadbled, F.; Sales de Gauzy, J.; Castex, M.P.; Brousset, P.; Gomez-Brouchet, A. Whole-exome sequencing in osteosarcoma reveals important heterogeneity of genetic alterations. Ann. Oncol. 2016, 27, 738-744. [CrossRef]

8. Vogelstein, B.; Papadopoulos, N.; Velculescu, V.E.; Zhou, S.; Diaz, L.A., Jr.; Kinzler, K.W. Cancer genome landscapes. Science 2013, 339, 1546-1558. [CrossRef]

9. Lawrence, M.S.; Stojanov, P.; Mermel, C.H.; Robinson, J.T.; Garraway, L.A.; Golub, T.R.; Meyerson, M.; Gabriel, S.B.; Lander, E.S.; Getz, G. Discovery and saturation analysis of cancer genes across 21 tumour types. Nature 2014, 505, 495-501. [CrossRef]

10. Chen, X.; Bahrami, A.; Pappo, A.; Easton, J.; Dalton, J.; Hedlund, E.; Ellison, D.; Shurtleff, S.; Wu, G.; Wei, L.; et al. Recurrent somatic structural variations contribute to tumorigenesis in pediatric osteosarcoma. Cell Rep. 2014, 7, 104-112. [CrossRef]

11. Gianferante, D.M.; Mirabello, L.; Savage, S.A. Germline and somatic genetics of osteosarcoma-connecting aetiology, biology and therapy. Nat. Rev. Endocrinol. 2017, 13, 480-491. [CrossRef] [PubMed]

12. Rickel, K.; Fang, F.; Tao, J. Molecular genetics of osteosarcoma. Bone 2017, 102, 69-79. [CrossRef] [PubMed]

13. Tranchevent, L.C.; Capdevila, F.B.; Nitsch, D.; De Moor, B.; De Causmaecker, P.; Moreau, Y. A guide to web tools to prioritize candidate genes. Brief. Bioinform. 2011, 12, 22-32. [CrossRef] [PubMed]

14. Bornigen, D.; Tranchevent, L.C.; Bonachela-Capdevila, F.; Devriendt, K.; De Moor, B.; De Causmaecker, P.; Moreau, Y. An unbiased evaluation of gene prioritization tools. Bioinformatics 2012, 28, 3081-3088. [CrossRef] [PubMed]

15. Moreau, Y.; Tranchevent, L.C. Computational tools for prioritizing candidate genes: Boosting disease gene discovery. Nat. Rev. Genet. 2012, 13, 523-536. [CrossRef] [PubMed]

16. Chen, J.; Aronow, B.J.; Jegga, A.G. Disease candidate gene identification and prioritization using protein interaction networks. BMC Bioinform. 2009, 10, 73. [CrossRef]

17. Huang da, W.; Sherman, B.T.; Lempicki, R.A. Systematic and integrative analysis of large gene lists using DAVID bioinformatics resources. Nat. Protoc. 2009, 4, 44-57. [CrossRef]

18. Huang da, W.; Sherman, B.T.; Lempicki, R.A. Bioinformatics enrichment tools: Paths toward the comprehensive functional analysis of large gene lists. Nucleic Acids Res. 2009, 37, 1-13. [CrossRef]

19. Supek, F.; Bosnjak, M.; Skunca, N.; Smuc, T. REVIGO summarizes and visualizes long lists of gene ontology terms. PLoS ONE 2011, 6, e21800. [CrossRef]

20. Szklarczyk, D.; Franceschini, A.; Wyder, S.; Forslund, K.; Heller, D.; Huerta-Cepas, J.; Simonovic, M.; Roth, A.; Santos, A.; Tsafou, K.P.; et al. STRING v10: Protein-protein interaction networks, integrated over the tree of life. Nucleic Acids Res. 2015, 43, D447-D452. [CrossRef]

21. Palla, G.; Derenyi, I.; Farkas, I.; Vicsek, T. Uncovering the overlapping community structure of complex networks in nature and society. Nature 2005, 435, 814-818. [CrossRef] [PubMed]

22. McDonald, E.R., 3rd; de Weck, A.; Schlabach, M.R.; Billy, E.; Mavrakis, K.J.; Hoffman, G.R.; Belur, D.; Castelletti, D.; Frias, E.; Gampa, K.; et al. Project DRIVE: A Compendium of Cancer Dependencies and Synthetic Lethal Relationships Uncovered by Large-Scale, Deep RNAi Screening. Cell 2017, 170, 577-592. [CrossRef] [PubMed]

23. Li, Z.; Ivanov, A.A.; Su, R.; Gonzalez-Pecchi, V.; Qi, Q.; Liu, S.; Webber, P.; McMillan, E.; Rusnak, L.; Pham, C.; et al. The OncoPPi network of cancer-focused protein-protein interactions to inform biological insights and therapeutic strategies. Nat. Commun. 2017, 8, 14356. [CrossRef] [PubMed]

24. Tejera, E.; Cruz-Monteagudo, M.; Burgos, G.; Sanchez, M.E.; Sanchez-Rodriguez, A.; Perez-Castillo, Y.; Borges, F.; Cordeiro, M.; Paz, Y.M.C.; Rebelo, I. Consensus strategy in genes prioritization and combined bioinformatics analysis for preeclampsia pathogenesis. BMC Med. Genomics 2017, 10, 50. [CrossRef] [PubMed]

25. Lopez-Cortes, A.; Paz, Y.M.C.; Cabrera-Andrade, A.; Barigye, S.J.; Munteanu, C.R.; Gonzalez-Diaz, H.; Pazos, A.; Perez-Castillo, Y.; Tejera, E. Gene prioritization, communality analysis, networking and metabolic integrated pathway to better understand breast cancer pathogenesis. Sci. Rep. 2018, 8, 16679. [CrossRef]

26. Srivastava, S.; Wang, S.; Tong, Y.A.; Hao, Z.M.; Chang, E.H. Dominant negative effect of a germ-line mutant p53: A step fostering tumorigenesis. Cancer Res. 1993, 53, 4452-4455. 
27. Friend, S.H.; Bernards, R.; Rogelj, S.; Weinberg, R.A.; Rapaport, J.M.; Albert, D.M.; Dryja, T.P. A human DNA segment with properties of the gene that predisposes to retinoblastoma and osteosarcoma. Nature 1986, 323, 643-646. [CrossRef]

28. Tsuchiya, T.; Sekine, K.; Hinohara, S.; Namiki, T.; Nobori, T.; Kaneko, Y. Analysis of the p16INK4, p14ARF, p15, TP53, and MDM2 genes and their prognostic implications in osteosarcoma and Ewing sarcoma. Cancer Genet. Cytogenet. 2000, 120, 91-98. [CrossRef]

29. Gokgoz, N.; Wunder, J.S.; Mousses, S.; Eskandarian, S.; Bell, R.S.; Andrulis, I.L. Comparison of p53 mutations in patients with localized osteosarcoma and metastatic osteosarcoma. Cancer 2001, 92, 2181-2189. [CrossRef]

30. Vassilev, L.T.; Vu, B.T.; Graves, B.; Carvajal, D.; Podlaski, F.; Filipovic, Z.; Kong, N.; Kammlott, U.; Lukacs, C.; Klein, C.; et al. In vivo activation of the p53 pathway by small-molecule antagonists of MDM2. Science 2004, 303, 844-848. [CrossRef]

31. Stratton, M.R.; Moss, S.; Warren, W.; Patterson, H.; Clark, J.; Fisher, C.; Fletcher, C.D.; Ball, A.; Thomas, M.; Gusterson, B.A.; et al. Mutation of the p53 gene in human soft tissue sarcomas: Association with abnormalities of the RB1 gene. Oncogene 1990, 5, 1297-1301. [PubMed]

32. Moll, U.M.; Petrenko, O. The MDM2-p53 interaction. Mol. Cancer Res. 2003, 1, 1001-1008. [PubMed]

33. Tamura, K.; Utsunomiya, J.; Iwama, T.; Furuyama, J.; Takagawa, T.; Takeda, N.; Fukuda, Y.; Matsumoto, T.; Nishigami, T.; Kusuhara, K.; et al. Mechanism of carcinogenesis in familial tumors. Int. J. Clin. Oncol. 2004, 9, 232-245. [CrossRef]

34. Sandberg, A.A.; Bridge, J.A. Updates on the cytogenetics and molecular genetics of bone and soft tissue tumors: Osteosarcoma and related tumors. Cancer Genet. Cytogenet. 2003, 145, 1-30. [CrossRef]

35. Poos, K.; Smida, J.; Maugg, D.; Eckstein, G.; Baumhoer, D.; Nathrath, M.; Korsching, E. Genomic heterogeneity of osteosarcoma-shift from single candidates to functional modules. PLoS ONE 2015, 10, e0123082. [CrossRef] [PubMed]

36. Sun, L.; Li, J.; Yan, B. Gene expression profiling analysis of osteosarcoma cell lines. Mol. Med. Rep. 2015, 12, 4266-4272. [CrossRef]

37. Shi, Z.; Zhou, H.; Pan, B.; Lu, L.; Wei, Z.; Shi, L.; Yao, X.; Kang, Y.; Feng, S. Exploring the key genes and pathways of osteosarcoma with pulmonary metastasis using a gene expression microarray. Mol. Med. Rep. 2017, 16, 7423-7431. [CrossRef]

38. Farhan, M.; Wang, H.; Gaur, U.; Little, P.J.; Xu, J.; Zheng, W. FOXO Signaling Pathways as Therapeutic Targets in Cancer. Int. J. Biol. Sci. 2017, 13, 815-827. [CrossRef]

39. Shaw, R.J.; Cantley, L.C. Ras, PI(3)K and mTOR signalling controls tumour cell growth. Nature 2006, 441, 424-430. [CrossRef]

40. Siqueira, M.F.; Flowers, S.; Bhattacharya, R.; Faibish, D.; Behl, Y.; Kotton, D.N.; Gerstenfeld, L.; Moran, E.; Graves, D.T. FOXO1 modulates osteoblast differentiation. Bone 2011, 48, 1043-1051. [CrossRef]

41. Kim, H.N.; Iyer, S.; Ring, R.; Almeida, M. The Role of FoxOs in Bone Health and Disease. Curr. Top. Dev. Biol. 2018, 127, 149-163. [CrossRef] [PubMed]

42. Tan, P.; Guan, H.; Xie, L.; Mi, B.; Fang, Z.; Li, J.; Li, F. FOXO1 inhibits osteoclastogenesis partially by antagnozing MYC. Sci. Rep. 2015, 5, 16835. [CrossRef]

43. Coomans de Brachene, A.; Demoulin, J.B. FOXO transcription factors in cancer development and therapy. Cell. Mol. Life Sci. 2016, 73, 1159-1172. [CrossRef] [PubMed]

44. Fu, Z.; Tindall, D.J. FOXOs, cancer and regulation of apoptosis. Oncogene 2008, 27, 2312-2319. [CrossRef]

45. Burgering, B.M.; Medema, R.H. Decisions on life and death: FOXO Forkhead transcription factors are in command when PKB/Akt is off duty. J. Leukoc. Biol. 2003, 73, 689-701. [CrossRef]

46. Moriishi, T.; Kawai, Y.; Komori, H.; Rokutanda, S.; Eguchi, Y.; Tsujimoto, Y.; Asahina, I.; Komori, T. Bcl2 deficiency activates FoxO through Akt inactivation and accelerates osteoblast differentiation. PLoS ONE 2014, 9, e86629. [CrossRef]

47. Guan, H.; Tan, P.; Xie, L.; Mi, B.; Fang, Z.; Li, J.; Yue, J.; Liao, H.; Li, F. FOXO1 inhibits osteosarcoma oncogenesis via Wnt/beta-catenin pathway suppression. Oncogenesis 2015, 4, e166. [CrossRef]

48. Tamborero, D.; Gonzalez-Perez, A.; Perez-Llamas, C.; Deu-Pons, J.; Kandoth, C.; Reimand, J.; Lawrence, M.S.; Getz, G.; Bader, G.D.; Ding, L.; et al. Comprehensive identification of mutational cancer driver genes across 12 tumor types. Sci. Rep. 2013, 3, 2650. [CrossRef]

49. Mendoza, M.C.; Er, E.E.; Blenis, J. The Ras-ERK and PI3K-mTOR pathways: Cross-talk and compensation. Trends Biochem. Sci. 2011, 36, 320-328. [CrossRef] 
50. Xu, Y.; Li, N.; Xiang, R.; Sun, P. Emerging roles of the p38 MAPK and PI3K/AKT/mTOR pathways in oncogene-induced senescence. Trends Biochem. Sci. 2014, 39, 268-276. [CrossRef]

51. De Luca, A.; Maiello, M.R.; D'Alessio, A.; Pergameno, M.; Normanno, N. The RAS/RAF/MEK/ERK and the $\mathrm{PI} 3 \mathrm{~K} / \mathrm{AKT}$ signalling pathways: Role in cancer pathogenesis and implications for therapeutic approaches. Expert Opin. Ther. Targets 2012, 16 (Suppl. 2), S17-S27. [CrossRef] [PubMed]

52. Han, G.; Wang, Y.; Bi, W. C-Myc overexpression promotes osteosarcoma cell invasion via activation of MEK-ERK pathway. Oncol. Res. 2012, 20, 149-156. [CrossRef] [PubMed]

53. Samatar, A.A.; Poulikakos, P.I. Targeting RAS-ERK signalling in cancer: Promises and challenges. Nat. Rev. Drug Discov. 2014, 13, 928-942. [CrossRef]

54. Daw, N.C.; Chou, A.J.; Jaffe, N.; Rao, B.N.; Billups, C.A.; Rodriguez-Galindo, C.; Meyers, P.A.; Huh, W.W. Recurrent osteosarcoma with a single pulmonary metastasis: A multi-institutional review. Br. J. Cancer 2015, 112, 278-282. [CrossRef]

55. Lamora, A.; Mullard, M.; Amiaud, J.; Brion, R.; Heymann, D.; Redini, F.; Verrecchia, F. Anticancer activity of halofuginone in a preclinical model of osteosarcoma: Inhibition of tumor growth and lung metastases. Oncotarget 2015, 6, 14413-14427. [CrossRef]

56. Diepenbruck, M.; Christofori, G. Epithelial-mesenchymal transition (EMT) and metastasis: Yes, no, maybe? Curr. Opin. Cell. Biol. 2016, 43,7-13. [CrossRef]

57. Jiang, W.G.; Sanders, A.J.; Katoh, M.; Ungefroren, H.; Gieseler, F.; Prince, M.; Thompson, S.K.; Zollo, M.; Spano, D.; Dhawan, P.; et al. Tissue invasion and metastasis: Molecular, biological and clinical perspectives. Semin. Cancer Biol. 2015, 35, S244-S275. [CrossRef]

58. Gross, A.C.; Cam, H.; Phelps, D.A.; Saraf, A.J.; Bid, H.K.; Cam, M.; London, C.A.; Winget, S.A.; Arnold, M.A.; Brandolini, L.; et al. IL-6 and CXCL8 mediate osteosarcoma-lung interactions critical to metastasis. JCI Insight 2018, 3. [CrossRef]

59. Liang, C.; Li, F.; Wang, L.; Zhang, Z.K.; Wang, C.; He, B.; Li, J.; Chen, Z.; Shaikh, A.B.; Liu, J.; et al. Tumor cell-targeted delivery of CRISPR/Cas9 by aptamer-functionalized lipopolymer for therapeutic genome editing of VEGFA in osteosarcoma. Biomaterials 2017, 147, 68-85. [CrossRef]

60. Weekes, D.; Kashima, T.G.; Zandueta, C.; Perurena, N.; Thomas, D.P.; Sunters, A.; Vuillier, C.; Bozec, A.; El-Emir, E.; Miletich, I.; et al. Regulation of osteosarcoma cell lung metastasis by the c-Fos/AP-1 target FGFR1. Oncogene 2016, 35, 2948. [CrossRef]

61. Kaya, M.; Wada, T.; Akatsuka, T.; Kawaguchi, S.; Nagoya, S.; Shindoh, M.; Higashino, F.; Mezawa, F.; Okada, F.; Ishii, S. Vascular endothelial growth factor expression in untreated osteosarcoma is predictive of pulmonary metastasis and poor prognosis. Clin. Cancer Res. 2000, 6, 572-577. [PubMed]

62. Yu, Y.; Luk, F.; Yang, J.L.; Walsh, W.R. Ras/Raf/MEK/ERK pathway is associated with lung metastasis of osteosarcoma in an orthotopic mouse model. Anticancer Res. 2011, 31, 1147-1152. [PubMed]

63. Himelstein, B.P.; Asada, N.; Carlton, M.R.; Collins, M.H. Matrix metalloproteinase-9 (MMP-9) expression in childhood osseous osteosarcoma. Med. Pediatr. Oncol. 1998, 31, 471-474. [CrossRef]

64. Liu, Y.; Wang, Y.; Teng, Z.; Chen, J.; Li, Y.; Chen, Z.; Li, Z.; Zhang, Z. Matrix metalloproteinase 9 expression and survival of patients with osteosarcoma: A meta-analysis. Eur. J. Cancer Care Engl. 2017, 26, e12364. [CrossRef]

65. Guleria, A.; Chandna, S. ATM kinase: Much more than a DNA damage responsive protein. DNA Repair 2016, 39, 1-20. [CrossRef]

66. Shiloh, Y.; Ziv, Y. The ATM protein kinase: Regulating the cellular response to genotoxic stress, and more. Nat. Rev. Mol. Cell Biol. 2013, 14, 197-210. [CrossRef]

67. Awasthi, P.; Foiani, M.; Kumar, A. ATM and ATR signaling at a glance. J. Cell Sci. 2016, 129, 1285. [CrossRef]

68. Ray, A.; Blevins, C.; Wani, G.; Wani, A.A. ATR- and ATM-Mediated DNA Damage Response Is Dependent on Excision Repair Assembly during G1 but Not in S Phase of Cell Cycle. PLoS ONE 2016, 11, e0159344. [CrossRef]

69. Blackford, A.N.; Jackson, S.P. ATM, ATR, and DNA-PK: The Trinity at the Heart of the DNA Damage Response. Mol. Cell 2017, 66, 801-817. [CrossRef]

70. Kovac, M.; Blattmann, C.; Ribi, S.; Smida, J.; Mueller, N.S.; Engert, F.; Castro-Giner, F.; Weischenfeldt, J.; Kovacova, M.; Krieg, A.; et al. Exome sequencing of osteosarcoma reveals mutation signatures reminiscent of BRCA deficiency. Nat. Commun. 2015, 6, 8940. [CrossRef] 
71. Nabetani, A.; Ishikawa, F. Alternative lengthening of telomeres pathway: Recombination-mediated telomere maintenance mechanism in human cells. J. Biochem. 2011, 149, 5-14. [CrossRef] [PubMed]

72. di Masi, A.; Cilli, D.; Berardinelli, F.; Talarico, A.; Pallavicini, I.; Pennisi, R.; Leone, S.; Antoccia, A.; Noguera, N.I.; Lo-Coco, F.; et al. PML nuclear body disruption impairs DNA double-strand break sensing and repair in APL. Cell Death Dis. 2016, 7, e2308. [CrossRef] [PubMed]

73. Lallemand-Breitenbach, V.; de The, H. PML nuclear bodies: From architecture to function. Curr. Opin. Cell Biol. 2018, 52, 154-161. [CrossRef]

74. Pickett, H.A.; Reddel, R.R. Molecular mechanisms of activity and derepression of alternative lengthening of telomeres. Nat. Struct. Mol. Biol. 2015, 22, 875-880. [CrossRef]

75. Voisset, E.; Moravcsik, E.; Stratford, E.W.; Jaye, A.; Palgrave, C.J.; Hills, R.K.; Salomoni, P.; Kogan, S.C.; Solomon, E.; Grimwade, D. Pml nuclear body disruption cooperates in APL pathogenesis and impairs DNA damage repair pathways in mice. Blood 2018, 131, 636-648. [CrossRef] [PubMed]

76. Neumann, A.A.; Watson, C.M.; Noble, J.R.; Pickett, H.A.; Tam, P.P.; Reddel, R.R. Alternative lengthening of telomeres in normal mammalian somatic cells. Genes Dev. 2013, 27, 18-23. [CrossRef] [PubMed]

77. Dilley, R.L.; Verma, P.; Cho, N.W.; Winters, H.D.; Wondisford, A.R.; Greenberg, R.A. Break-induced telomere synthesis underlies alternative telomere maintenance. Nature 2016, 539, 54-58. [CrossRef]

78. Kim, J.Y.; Brosnan-Cashman, J.A.; An, S.; Kim, S.J.; Song, K.B.; Kim, M.S.; Kim, M.J.; Hwang, D.W.; Meeker, A.K.; Yu, E.; et al. Alternative Lengthening of Telomeres in Primary Pancreatic Neuroendocrine Tumors Is Associated with Aggressive Clinical Behavior and Poor Survival. Clin. Cancer Res. 2017, 23, 1598-1606. [CrossRef]

79. Singhi, A.D.; Liu, T.C.; Roncaioli, J.L.; Cao, D.; Zeh, H.J.; Zureikat, A.H.; Tsung, A.; Marsh, J.W.; Lee, K.K.; Hogg, M.E.; et al. Alternative Lengthening of Telomeres and Loss of DAXX/ATRX Expression Predicts Metastatic Disease and Poor Survival in Patients with Pancreatic Neuroendocrine Tumors. Clin. Cancer Res. 2017, 23, 600-609. [CrossRef]

80. Liau, J.Y.; Tsai, J.H.; Jeng, Y.M.; Lee, J.C.; Hsu, H.H.; Yang, C.Y. Leiomyosarcoma with alternative lengthening of telomeres is associated with aggressive histologic features, loss of ATRX expression, and poor clinical outcome. Am. J. Surg. Pathol. 2015, 39, 236-244. [CrossRef]

81. Fogli, A.; Demattei, M.V.; Corset, L.; Vaurs-Barriere, C.; Chautard, E.; Biau, J.; Kemeny, J.L.; Godfraind, C.; Pereira, B.; Khalil, T.; et al. Detection of the alternative lengthening of telomeres pathway in malignant gliomas for improved molecular diagnosis. J. Neurooncol. 2017, 135, 381-390. [CrossRef] [PubMed]

82. Chong, J.L.; Wenzel, P.L.; Saenz-Robles, M.T.; Nair, V.; Ferrey, A.; Hagan, J.P.; Gomez, Y.M.; Sharma, N.; Chen, H.Z.; Ouseph, M.; et al. E2f1-3 switch from activators in progenitor cells to repressors in differentiating cells. Nature 2009, 462, 930-934. [CrossRef] [PubMed]

83. Hayden, M.S.; Ghosh, S. Signaling to NF-kappaB. Genes Dev. 2004, 18, 2195-2224. [CrossRef] [PubMed]

84. Seoane, J.; Gomis, R.R. TGF-beta Family Signaling in Tumor Suppression and Cancer Progression. Cold Spring Harb. Perspect. Biol. 2017, 9, a022277. [CrossRef]

85. Pohl, T.; Gugasyan, R.; Grumont, R.J.; Strasser, A.; Metcalf, D.; Tarlinton, D.; Sha, W.; Baltimore, D.; Gerondakis, S. The combined absence of NF-kappa B1 and c-Rel reveals that overlapping roles for these transcription factors in the B cell lineage are restricted to the activation and function of mature cells. Proc. Natl. Acad. Sci. USA 2002, 99, 4514-4519. [CrossRef]

86. Liekens, A.M.; De Knijf, J.; Daelemans, W.; Goethals, B.; De Rijk, P.; Del-Favero, J. BioGraph: Unsupervised biomedical knowledge discovery via automated hypothesis generation. Genome. Biol. 2011, 12, R57. [CrossRef]

87. Wu, X.; Jiang, R.; Zhang, M.Q.; Li, S. Network-based global inference of human disease genes. Mol. Syst. Biol. 2008, 4, 189. [CrossRef]

88. Pinero, J.; Queralt-Rosinach, N.; Bravo, A.; Deu-Pons, J.; Bauer-Mehren, A.; Baron, M.; Sanz, F.; Furlong, L.I. DisGeNET: A discovery platform for the dynamical exploration of human diseases and their genes. Database 2015, 2015, bav028. [CrossRef]

89. Fontaine, J.F.; Priller, F.; Barbosa-Silva, A.; Andrade-Navarro, M.A. Genie: Literature-based gene prioritization at multi genomic scale. Nucleic Acids Res. 2011, 39, W455-W461. [CrossRef]

90. Jourquin, J.; Duncan, D.; Shi, Z.; Zhang, B. GLAD4U: Deriving and prioritizing gene lists from PubMed literature. BMC Genom. 2012, 13 (Suppl. 8), S20. [CrossRef] 
91. Guney, E.; Garcia-Garcia, J.; Oliva, B. GUILDify: A web server for phenotypic characterization of genes through biological data integration and network-based prioritization algorithms. Bioinformatics 2014, 30, 1789-1790. [CrossRef] [PubMed]

92. Yang, H.; Robinson, P.N.; Wang, K. Phenolyzer: Phenotype-based prioritization of candidate genes for human diseases. Nat. Methods 2015, 12, 841-843. [CrossRef] [PubMed]

93. Cheng, D.; Knox, C.; Young, N.; Stothard, P.; Damaraju, S.; Wishart, D.S. PolySearch: A web-based text mining system for extracting relationships between human diseases, genes, mutations, drugs and metabolites. Nucleic Acids Res. 2008, 36, W399-W405. [CrossRef] [PubMed]

94. Yue, P.; Melamud, E.; Moult, J. SNPs3D: Candidate gene and SNP selection for association studies. BMC Bioinform. 2006, 7, 166. [CrossRef] [PubMed]

95. Lambert, S.A.; Jolma, A.; Campitelli, L.F.; Das, P.K.; Yin, Y.; Albu, M.; Chen, X.; Taipale, J.; Hughes, T.R.; Weirauch, M.T. The Human Transcription Factors. Cell 2018, 175, 598-599. [CrossRef]

96. Yevshin, I.; Sharipov, R.; Kolmykov, S.; Kondrakhin, Y.; Kolpakov, F. GTRD: A database on gene transcription regulation-2019 update. Nucleic Acids Res. 2019, 47, D100-D105. [CrossRef]

97. Shannon, P.; Markiel, A.; Ozier, O.; Baliga, N.S.; Wang, J.T.; Ramage, D.; Amin, N.; Schwikowski, B.; Ideker, T. Cytoscape: A software environment for integrated models of biomolecular interaction networks. Genome Res. 2003, 13, 2498-2504. [CrossRef]

(C) 2020 by the authors. Licensee MDPI, Basel, Switzerland. This article is an open access article distributed under the terms and conditions of the Creative Commons Attribution (CC BY) license (http://creativecommons.org/licenses/by/4.0/). 